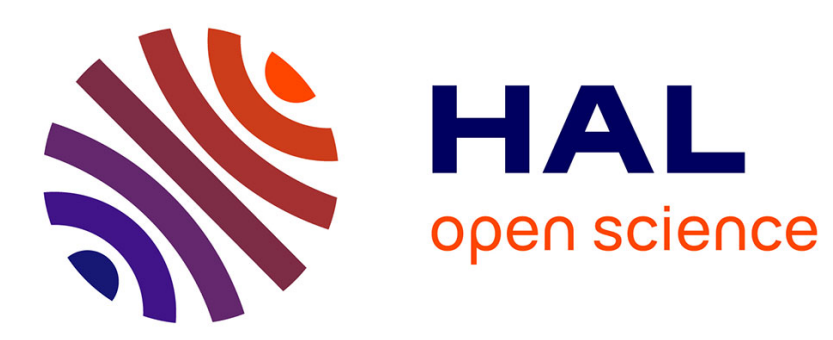

\title{
Opening a Pandora's Box: Modeling World Trade Patterns at the 2035 Horizon
}

\author{
Lionel Fontagné, Jean Fouré
}

\section{To cite this version:}

Lionel Fontagné, Jean Fouré. Opening a Pandora's Box: Modeling World Trade Patterns at the 2035 Horizon. 2013. hal-01299851

\section{HAL Id: hal-01299851 \\ https://hal.science/hal-01299851}

Preprint submitted on 8 Apr 2016

HAL is a multi-disciplinary open access archive for the deposit and dissemination of scientific research documents, whether they are published or not. The documents may come from teaching and research institutions in France or abroad, or from public or private research centers.
L'archive ouverte pluridisciplinaire HAL, est destinée au dépôt et à la diffusion de documents scientifiques de niveau recherche, publiés ou non, émanant des établissements d'enseignement et de recherche français ou étrangers, des laboratoires publics ou privés. 


\section{World Trade Organization \\ Economic Research and Statistics Division}

\section{Opening a Pandora's Box:}

Modeling World Trade Patterns at the 2035 Horizon

\section{Lionel Fontagné \& Jean Fouré}

Manuscript date: August 2, 2013

Disclaimer: This is a working paper, and hence it represents research in progress. This paper represents the opinions of the author(s), and is the product of professional research. It is not meant to represent the position or opinions of the WTO or its Members, nor the official position of any staff members. Any errors are the fault of the author(s). Copies of working papers can be requested from the divisional secretariat by writing to: Economic Research and Statistics Division, World Trade Organization, Rue de Lausanne 154, CH 1211 Geneva 21, Switzerland. Please request papers by number and title. 


\title{
OPENING A PANDORA's BoX: \\ Modeling World Trade Patterns at THE 2035 Horizon \\ Lionel Fontagné ${ }^{*} \&$ Jean Fouré ${ }^{\ddagger}$
}

August 2, 2013

\begin{abstract}
Economic projections for the world economy, particularly in relation to the construction of Computable General Equilibrium (CGE) baselines, are generally rather conservative and take scant account of the wide range of possible evolutions authorized by the underlying economic mechanisms considered. Against this background, we adopt an 'open mind' to the projection of world trade trajectories. Taking a 2035 horizon, we examine how world trade patterns will be shaped by the changing comparative advantages, demand, and capabilities of different regions. We combine a convergence model fitting three production factors (capital, labor and energy) and two factor-specific productivities, alongside a dynamic CGE model of the world economy calibrated to reproduce observed elasticity of trade to income. Each scenario involves three steps. First, we project growth at country level based on factor accumulation, educational attainment and efficiency gains, and discuss uncertainties related to our main drivers. Second, we impose this framework (demographics, gross domestic product, saving rates, factors and current account trajectories) on the CGE baseline. Third, we implement trade policy scenarios (tariffs as well as non-tariff measures in goods and services), in order to get factor allocation across sectors from the model as well as demand and trade patterns. We show that the impact of changing baselines is greater than the impact of a policy shock on the order of magnitude of changes in world trade patterns, which points to the need for care when designing CGE baselines.
\end{abstract}

JEL Classification: $\quad$ E23, E27, F02, F17, F47

Key Words: $\quad$ Growth, Macroeconomic Projections, Dynamic Baselines

\footnotetext{
* PSE (Paris 1) and CEPII. Email: lionel.fontagne@univ-paris1.fr

‡ CEPII. Email: jean.foure@cepii.fr
} 


\section{INTRODUCTION}

What will be the main patterns of world trade in the 2030s? This is an important question since it refers to whether the institutional environment of international trade will produce a level playing-field. There is much uncertainty in such projections. There are two main sources of errors of judgment: projection of the drivers of international trade, and the basic unpredictability of some key variables which is an irreducible source of error.

Thus, it is essential to properly project the drivers of international trade: conditional on trade frictions and prices, the volume of trade is basically a function of countries' Gross Domestic Product (GDP), according to the extensively documented principle of gravity. The key here is to have a sound representation of economic growth, providing GDP projections for the largest number of world countries. Is it best to adopt a very detailed model of growth that includes regulations for example, or a detailed representation of the public sector, or to focus on the main mechanisms and treat national idiosyncrasies as unobservable? There is a trade-off between restricting projections to the set of OECD countries (plus a handful of emerging economies), and including a much larger set of countries in a more stylized growth model.

The second prerequisite is to acknowledge the unpredictability of certain key variables. Energy prices could vary widely over the next 20 years, not primarily as the result of uncertainties surrounding economic growth, but due to geopolitical tensions (e.g. Middle-East) or technological breakthroughs (e.g. shale gas or jumps in energy efficiency). Female participation in the labour force is expected to increase as countries develop, but this driver of growth is also subject to uncertainties. Education convergence may speed up or may be hampered, with sizeable impacts on productivity. The future of international capital mobility is also very uncertain. Productivity convergence may accelerate or decelerate as a result of methods of technology transfer and approaches to firm mobility. Lastly, we may observe large migrations flows as a result of unexpected push factors, while fertility rates are highly uncertain.

Against this background, this paper has a methodological aim. First, to demonstrate how to feed into a dynamic sectoral model of the world economy projected economic growth for a larger set of countries. These projections use a stylized conditional convergence model of economic growth fitting three factors (capital, labor and energy), two types of technological progress (total factor productivity TFP - of the capital-labor combination, and energy efficiency) and international capital mobility. We also project saving rates (based on a life cycle hypothesis) and current accounts. GDP and saving are projected at the country level, while constraints are imposed in terms of global balance between saving and investment. The second aim is to illustrate how induced GDP, saving, energy efficiency and current account trajectories to 2035 can be imposed on a Computable General Equilibrium (CGE) model of the world economy, relying on identical assumptions about population, labor force, education and current accounts. The CGE, in turn, will provide factor allocation (across sectors), demand patterns (preferences and budget shares) and, thus, trade patterns, conditional on trade costs.

In addition to illustrating step by step how best to combine the modeling tools, our exercise adopts open-minded assumptions about the evolution of the key drivers of growth. For example, we give free rein to economic mechanisms, hence opening a Pandora's Box of growth projections. We examine the impact on economic growth of large and combined shocks to its main drivers. Not all shocks will affect developing and developed economies in the same way. We combine the effects of these shocks with possible evolutions in trade costs. In addition to energy prices, we consider the situation of a tariff war driving countries beyond the legal World Trade Organization (WTO) framework, to postTokyo Round tariff levels. We examine the impact of generalized inspection of shipments, as a response to pandemics or terrorism. Finally we address changes in the barriers to services trade. The 
aim is not to suggest that any of these scenarios is plausible given current information on the world economy. Instead we want to show how common modeling tools can be combined to characterize the broad range of possible world trade patterns associated with the presence of high uncertainty. We conclude that the impact of changing baselines is greater than the impact of a policy shock on the order of magnitude of changes in world trade patterns, which points to the need for care when designing CGE baselines.

This methodological paper contributes to a recent and growing body of literature on long term prospects for the world economy. Qualitative scenarios combining the two modeling frameworks as a background to a more multidisciplinary approach centered on Europe were developed at the 2050 horizon for the European Commission (EC, 2012). The International Monetary Fund (IMF, 2011) uses a partial equilibrium approach to address the consequences of reductions in exchange rate misalignment with trade patterns in the presence of global value chains and possibly imperfect pass through. Fontagné et al. (2013) proposes possible scenarios to be used as background for environmental studies, and considers the 2100 horizon in order to explore methodological issues associated with the use of long term dynamic baselines in CGE models. World Bank (2007), which is closer to our approach, relies on a multisectoral model of the world economy comparable to MIRAGE, to sketch scenarios for the world economy at the 2030 horizon. None of these studies use an explicit growth model and the scenarios are driven by assumptions about TFP imposed on the CGE. In contrast, Petri and Zhai (2013) rely on Asian Development Bank growth projections using a growth model similar to ours (ADB, 2011). They use this GDP series to derive scenarios at the 2050 horizon, with a CGE model on which assumptions about TFP, higher food prices, higher energy prices, or protectionism are imposed. Finally, Anderson and Strutt (2012) consider the 2030 horizon and build a baseline for the GTAP CGE model by drawing on both ADB (2011) and Fouré et al. (2010).

The value added of the present paper is to highlight the technical issues and the wide range of uncertainty raised by combining macroeconomic and multisectoral models which open a Pandora's box of long term projections. For example: (i) it builds scenarios for some 150 countries, taking account of the interactions among capital mobility and trade in goods and services; (ii) it implements scenarios in a consistent way in both the growth (Macroeconometrics of the Global Economy MaGE) and multisectoral dynamic CGE (MIRAGE) models; (iii) the scenarios tackle a wide range of potentialities paying close attention to decomposition of effects. To our knowledge, this is, the only exercise so far on such a scale, at the 2035 horizon, adopting a methodology of consistent scenario construction for the growth and the CGE models.

The rest of the paper is organized as follows. Assumptions related to growth projections and our scenarios are presented in Section 1. Section 2 describes the methodology and the scenarios are implemented in the growth model in Section 3. Section 4 summarizes the results of the global and sectoral models of the world economy. The last section concludes. ${ }^{1}$

\footnotetext{
1 A companion paper discusses our main findings in depth: Fontagné L., Fouré J. and A. Keck (2013), Simulating world trade in the decades ahead: Driving forces and policy implications. WTO working paper, Geneva.
} 


\section{MODELING GROWTH PROJECTIONS AND DESIGNING SCENARIOS FOR THE WORLD ECONOMY}

This paper is positioned at the junction between three strands of the applied economic literature: (i) economic growth projections; (ii) design of dynamic baselines in applied general equilibrium modeling with a focus on the environment; and (iii) design of medium and long term scenarios for the world economy. The first two are not independent: design of dynamic baselines relies on the first literature strand (GDP driven baselines), or provides GDP projections directly based on assumptions about changes in sector-specific TFP (TFP driven baselines). The third stream of literature combines quantitative elements (potentially provided by projections and baselines) with qualitative and sometimes multidisciplinary expertise on the main drivers of economic, social and environmental change. Below, we briefly survey the literatures related to growth projections, dynamic baselines and scenario building.

\subsection{Growth projections}

Increased interest in long-term economic-related issues, such as environment depletion and energy scarcity, has motivated several growth projection exercises. The business community initiated documentation of the huge shift towards the emerging economies (Wilson and Purushothaman, 2003; Ward, 2011), which was added to by work from international institutions. With some exceptions (Duval and de la Maisonneuve, 2010, Johansson et al., 2012), academic work in this area was sparse, leading to a lack of well-documented and economically-grounded projection models. This can be explained by the huge uncertainties surrounding projections that rarely prove accurate and are conditional on changes in the geopolitical context. Nevertheless, long-term investigations are a prerequisite for much downstream analysis, such as provided in this paper to address future patterns of world trade.

This lack of attention contrasts with the importance of economic growth factors in the economic literature. Starting from the standard neo-classical Solow model, mechanisms for production factor accumulation have been identified, for instance, in the demographic determinants of saving (see, for instance, Masson et al., 1998) and capital formation (Feldstein and Horioka, 1980), or in human capital catch-up and productivity improvements (Aghion and Howitt, 1992). Long-term growth projection models build on this vast literature by combining existing analyses.

At least three drivers are common to all empirical studies: capital stocks, labour force and TFP. These factors are taken into account by Wilson and Purushothaman (2003), which combines existing labour force projections, constant investment rates, and a convergence scenario for TFP. Duval and de la Maisonneuve (2010) identify human capital per worker as a driver, and calibrate conditional convergence scenarios among countries for each of these four determinants. Using a similar framework, Johansson et al. (2012) restrict their analysis to a smaller number of countries, but emphasize the impact of structural and fiscal policies (retirement age, trade regulation, public debt, credit availability). Finally, Fouré et al. (2013) introduce energy as a production factor along with energy-specific productivity, and base their projection framework on econometric analysis of both convergence mechanisms and structural relations. Comparing the projections in these papers we observe sizeable differences in the results. In Fouré et al. (2013), the share of China in world GDP at 2050 is almost twice the share projected by Duval and de la Maisonneuve. These differences call for transparency in assumptions and modeling frameworks and 'open-minded' scenarios when introducing projections into dynamic CGEs. 


\subsection{Dynamic baselines}

Large scale policy simulations generally rely on multisectoral dynamic models of the word economy. CGE is the most commonly used modeling framework. Policies are simulated as shocks and then the deviation of the variables of interest from their reference trajectory is computed. It could be argued that the modeler's interest is in the deviation, not the initial equilibrium. However, this would be flawed reasoning if the focus is medium or long run policies: an economic policy affecting China would have a dramatically different impact on the world economy were China twice as large, which will be the case in less than ten years at current growth trends.

Since the model is exploited to determine capital accumulation, energy and primary resources prices, it is necessary to supplement it with world data including demographics. However, since CGE models generally do not describe the intrinsic mechanisms of growth (conditional convergence) they provide neither a satisfactory representation of efficiency gains from combining production factors, nor plausible trajectories for countries at different levels of development. Accordingly, it is necessary to constrain the CGE to reproduce a pre-defined GDP growth path or a pre-defined TFP path for each world country (or region). This is the aim of dynamic baselines.

Many baselines focus on the period up to 2020 (e.g. the GTAP model), but some exercises extend to 2050 (e.g. the Linkage model). Relying on an ambitious approach, Fontagné et al. (2013) tentatively consider the 2100 horizon in order to provide environmental studies with a theoretically consistent baseline of the world economy. Whatever the horizon, the building blocks of a baseline are the same.

The first step is projection of a general trajectory of world growth, based on simple and robust economic mechanisms. There are two competing approaches to CGE modelling. The first option is to build a scenario for factor productivity growth in order to recover GDP from the CGE model. The second is to build a GDP scenario such that the model recovers the relevant TFP gains.

Recovering GDP from TFP growth assumptions has the advantage that availability of detailed data on demographics or education is not a limiting factor. Moreover, it allows different sector specific trajectories to be encompassed without over-constraining the model. However, this approach is very sensitive to assumptions related to TFP growth and its determinants. For instance, the EPPA model (Paltsev et al., 2005) assumes identical logistic productivity growth for all countries and sectors, and does not implement capital productivity.

The symmetric approach of imposing GDP growth trajectories onto a CGE, and recovering the productivity gains, is more data demanding since it is necessary, first, to project growth for every country. Its main advantage is that it enables proper modeling of growth by taking account of conditional convergence and possibly different types of technical progress, in line with the vast literature on macroeconomic growth. This is a very important advantage if the interest is in long run modeling of different kinds (mature, emerging, developing) of economies. Also, this approach allows greater reliance on the macro projections in the literature (see Fouré et al., 2013 for a short review). For instance, the main projections used in the GTAP model and earlier versions of MIRAGE (Decreux and Valin, 2007) were provided by the World Bank (Ianchovichina and McDougall, 2000).

The only crucial assumption in GDP-driven CGEs is the relative dynamism of productivity in broad sectors. Several approaches to this difficult issue have been proposed. The LINKAGE model (Van der Mensbrugghe, 2006-a) adds a sector-specific component - labor-only productivity - to endogenous national TFP. This approach results in: (i) a constant exogenous agricultural TFP; and (ii) a constant 2percentage points difference between industry and services sector productivity (the former being more productive). There is a separate literature on agriculture-specific productivity that draws on Nin et al. (2001). Coelli and Rao (2005) and Ludena et al. (2007) depart from the usual analysis of yields, and 
start from non-parametric productivity indices based on the use of agricultural inputs. They show that productivity in agriculture is not constant, and that its growth rate is heterogeneous across countries.

In addition to these efforts to provide the modeling community with dynamic baselines for their policy simulations that rely on CGEs, a related literature stream specifically tackles environmental issues. Two key issues are raised: first the productivity of energy and its impact on $\mathrm{CO}_{2}$ emissions, and second, natural resources scarcity and it's the direct link to energy prices. In both cases, assumptions focus on one variable such that the other adjusts.

Similar to environmental baselines, the first approach is to rely on $\mathrm{CO}_{2}$ emissions from other institutions (or, equivalently, on energy demand), such as in the PACE model (Böhringer et al., 2009). In this case, improvements to the carbon intensity of goods are deduced, although no comprehensive framework for energy consumption is developed. In addition, particular attention has to be given to the coherence between the emissions projections' underlying growth assumptions and the growth model projections because $\mathrm{CO}_{2}$ emissions depend heavily on economic activity.

The second approach consists of developing a scenario for Autonomous Energy Efficiency Improvements (AEEI) as in the EPPA model. These AEEI encompass non-price induced, technologydriven productivity changes. An exogenous time trend for energy productivity is imposed in order to control for the evolution of demand reduction, which scales production sectors' use of energy per unit of output. These AEEI are specific to broad regions (10 regions in the EPPA) with two distinct profiles. On the one hand, China and the Developed Countries face a regularly increasing AEEI. On the other hand, other countries' AEEI first decrease (up to around 2035) and then increase at different rates. These discrepancies are driven by the empirical observation that energy productivity has regularly increased in countries with well-developed industry and services sectors, and have stagnated or even decreased in industrializing countries. The Linkage model implements a mixed framework, in which energy demands are imposed to recover productivity changes with the exception of crude oil consumption which is driven by an exogenous productivity scenario.

A problematic issue related to $\mathrm{CO}_{2}$ emissions and energy consumption is the limitation inherent to CGE modeling. These two variables are measured in physical quantities, although variables in CGE models traditionally are in dollars at constant prices. Laborde and Valin (2011) point out that using Constant Elasticity of Substitution (CES) functional forms for monetary values leads to incoherence in substitutions when commodities are relatively homogenous, as is the case for energy goods. There are two ways to deal with this issue. One can build a world price matrix for physical quantities of energy goods, such that they account for changes in both value and quantity. A more parsimonious approach is to impose on the model that production, consumption and trade are coherent in both monetary units and physical quantities.

Finally, the question of natural resource depletion can be approached in two ways. As underlined by Paltsev et al. (2005), long run dynamics of energy prices are captured by natural resources depletion. Therefore, it is possible to model this depletion and deduce the corresponding energy prices, or to do the reverse. The first solution is chosen by the EPPA model, which incorporates resource-specific natural resources use as well as additional recoveries. The second involves exogenously fixing energy prices, as in the ENV-Linkage model (an option also available in EPPA), such that natural resources adjust to match targeted prices. The assumption in ENV-Linkage is to rely on IEA's world price projections up to 2030 and then assume a 1\% growth in oil prices. 


\subsection{Scenario design}

In what follows, we briefly survey some medium term scenarios of the world economy relying on a combination of growth projection and CGE modeling. These exercises were developed by the World Bank, the OECD, Petri and Zhai (based on Asian Development Bank projections) and Anderson and Strutt (based on Asian development Bank and our own projections).

World Bank (2007) relies on LINKAGE (a multisectoral model of the world economy comparable to MIRAGE, described in van der Mensbrugghe, 2006) to draw scenarios for the world economy at the 2030 horizon. Instead of recovering TFP from the CGE on which GDP and factor accumulation would be imposed, TFP assumptions are imposed on the CGE to obtain GDP. In addition, energy efficiency is assumed to improve exogenously by $1 \%$ per year worldwide. Energy efficiency is derived theoretically and projected on a country basis in MaGE, before being introduced in the CGE in our exercise. Finally, international trade costs are assumed to decline by $1 \%$ per year, in line with our own pre-experiment aimed at mimicking the historical income elasticity of international trade. This exercise was calibrated on the GTAP-2001 database (we used GTAP-2004 for MIRAGE).

Petri and Zhai (2013) combine Asian Development Bank growth projections at the 2050 horizon (ADB, 2011) with a CGE model in order to develop their scenarios. In addition to a focus on Asia rather than a world-wide perspective, the big difference from our study is not the horizon considered, but the methodology used to design the scenarios. Our approach involves three steps. We first design a business-as-usual scenario of world growth, and run a pre-experiment in order that our CGE reproduces income trade elasticity observed in the past. Second we construct two scenarios for the growth model, which are then imposed on the CGE in a consistent way. Third, we shock the CGE, completing our two scenarios with evolutions, such as possible changes in transaction costs, that can be tackled only by the CGE. In contrast, Petri and Zhai use a business-as-usual macroeconomic baseline and then proceed to our third step. ${ }^{2}$ This is an important difference since many of the assumptions of our scenarios (e.g. fertility, female participation in the labor market, education catch up) will have cascading effects for growth and trade, channeled through the different mechanisms in the two models.

Anderson and Strutt (2012) consider the 2030 horizon and build a baseline for the GTAP CGE model. They combine growth rates for GDP, investment and population from ADB (2011), with our (previous set of) projections for the world economy (Fouré et al., 2010) for those countries not included in the ADB projections. Finally, skilled and unskilled labor growth rate projections are from Chappuis and Walmsley (2011). Historical trends for agricultural land from the Food and Agriculture Organization (FAO), and mineral and energy raw material reserves from British Petroleum (BP, 2010), are extended over the next two decades. TFP growth rates are recovered from the CGE model. Scenarios are implemented (as in Petri and Zhai) directly in the CGE: they show a drop in TFP and further trade liberalization. Implications for world trade are derived. Two drawbacks to this approach are the combining of different growth models (ADB and MaGE-V1.2), and the implementation of scenarios directly in the CGE rather than using two modeling frameworks. Also, the scenarios can be questioned since further trade liberalization is not necessarily an outcome for the future economy. Anderson and Strutt acknowledge the absence of scenarios for trade costs, transport costs and current account imbalances, all dimensions included in our analysis.

\footnotetext{
2 Their simpler approach allows deeper developments in terms of income distribution. While we rely on a representative household and two labor categories (skilled, unskilled), Petri and Zhai supplement their CGE with an income distribution module which allocates total consumption to four income bins.
} 
Finally, the OECD (Chateau et al., 2012) uses the ENV-Growth model in order to design climate change scenarios in line with the five Shared Socioeconomic Pathways (SSP) developed by the Integrated Assessment Modeling Consortium. These scenarios are organized around the trade-off between climate change mitigation and adaptation, both translated into demographic (population and education), technological (catch-up speed and frontier growth) and natural resources (prices and available resources) related scenarios, and both implemented in the growth model. They clearly identify the drivers of growth as capital accumulation, TFP, labor force (and to a lesser extent human capital and energy), but cannot directly investigate the saving-investment relationship due to the original specifications of the SSPs, nor explicitly deal with uncertainty in labor force participation with trade integration (except via positive externalities on in TFP). These scenarios are being integrated with the OECD's ENV-Linkages CGE model, following a method similar to ours; to our knowledge, results are not yet available. 


\section{WHAT WE DO}

This paper adopts the GDP-driven CGE approach described above. To proceed, we start with a growth model derived theoretically, estimated, and used to make projections for more than 140 countries. The building blocks of this model are conditional convergence (based inter alia on human capital accumulation), energy use and efficiency, demographic transition, and saving behavior. This first step is performed with the MaGE model (Fouré et al., 2013). Using this framework, we implement scenarios for the world economy. The second step consists of imposing GDP trajectories (depicted in the various scenarios) from our growth model onto the CGE, and using sector-specific constraints and exogenous agricultural productivity to depict coherent sector disaggregation. To proceed we use a new version of MIRAGE, known as MIRAGE-e - the 'e' referring to environment (Fontagné et al., 2013). The CGE provides sector decomposition of growth, factor allocation, country specialization and world trade patterns, these last being our ultimate objective. In the second stage, additional shocks are imposed on the CGE. This two-step approach is ultimately mobilized to build alternative scenarios of the world economy.

Below we describe the growth model (MaGE), the CGE model (MIRAGE-e), and the design of the scenarios.

\subsection{The growth model}

Projections of world macroeconomic trends are elaborated with the MaGE model proposed in Fouré et al. (2013). Based on a three-factor (capital, labor, energy) and two-productivity (capital-labor and energy-specific) production function, MaGE is a supply-side oriented macroeconomic growth model, defined at country level for 147 countries. It consists of three steps. First, production factor and productivity data are collected for 1980 to 2009. Second, behavioral relations are estimated econometrically for factor accumulation and productivity growth, based on these data. Third, these relations are used to project the world economy.

Using World Bank, United Nations and International Labour Organization data, we built a dataset of production factors and economic growth for the period 1980-2009. Our theoretical framework consists of a CES production function of energy and a Cobb-Douglas bundle of capital and labor. This theoretical framework allows recovery of energy-specific productivity from the profit-maximization program of the representative firm, while capital and labor productivity are recovered as a Solow residual.

Behavioural relations are econometrically estimated from this dataset for population, capital accumulation and productivity. Population projections are given by United Nations population projections, split across 5-year age bins. For each of these age groups, we estimate education and then deduce labor force participation. Educational attainment follows a catch-up process to the leaders in secondary and tertiary education, with region-specific convergence speeds. While male labor force participation follows the logistic relation determined by the International Labor Organization, female participation changes with education level.

Capital accumulates according to a permanent-inventory process with a constant deprecation rate. On the one hand, investment depends on saving with a non-unitary error-correction relationship which differentiates long-term correlation between saving and investment and annual adjustments around this trend. Because of the significant differences we found between OECD and non-OECD members, both levels of estimation are conducted separately for the two country groups. On the other hand, saving depends on the age structure of the population consistent with both the life-cycle hypothesis and economic growth. 
Capital-labor and energy productivity follow catch-up behavior with the best-performing countries. The former is conditional on and fuelled by education level (tertiary education for innovation and secondary education for imitation); the latter is modified by the level of development to reflect the sectoral organization of countries.

We are able to recover GDP and factor projections given the theoretical link between energy productivity, energy price (exogenously imposed) and energy consumption.

\subsection{The CGE model}

We use a new version of the multisectoral, multi-regional CGE model MIRAGE (Bchir et al., 2002; Decreux and Valin, 2007), which was developed and has been used extensively to assess trade liberalization and agricultural policy scenarios (e.g., Bouët et al., 2005, 2007). For simplicity, we use the version of the model fitting perfect competition. The MIRAGE-e version of the model proposes a different modeling of energy use, and introduces modling of CO2 emissions (Fontagné et al., 2013).

MIRAGE-e was adapted to the exercise conducted here. MIRAGE has a sequential dynamic recursive set-up which is consistent with the output of MaGE: capital accumulation and current account will be driven by the results of the first step of our exercise. Macroeconomic closure consists of having the share of each region in global current accounts imbalances varying yearly according to the projections from MaGE.

On the supply side, in this perfect competition version of MIRAGE, each sector is modeled as a representative firm, which combines value-added and intermediate consumption in fixed shares. Value-added is a bundle of imperfectly substitutable primary factors (capital, skilled and unskilled labor, land and natural resources) and energy.

We assume full employment of primary factors, whose growth rates are set exogenously based on MaGE projections. Installed capital is assumed to be immobile (sector-specific), while investment is allocated across sectors according to their rates of return. The overall stock of capital evolves by combining investment and a constant depreciation rate of capital. Skilled and unskilled labor are perfectly mobile across sectors, while land is assumed to be imperfectly mobile between agricultural sectors, and natural resources are sector-specific.

Firms' energy consumption comprises five energy goods (electricity, coal, oil, gas and refined petroleum), which are aggregated in a single bundle that mainly substitutes for capital. There is no consensus in the literature about the extent to which capital and energy are substitutable. It can vary according to the vintage of capital (e.g. from 0.12 to 1 in the GREEN model), or be fixed between 0.5 (GTAP-E model) and 0.8 (PACE model). Since energy consumption is very sensitive to this elasticity of substitution, its calibration is vitally important. We choose to reproduce stylized energy consumption trends as in International Energy Agency projections to 2025 (IEA, 2011), which leads us to calibrate this elasticity as in GTAP-E. The architecture of the energy bundle defines three levels of substitution. Energy used can be delivered by electricity or fossil fuels. Fossil fuels can be coal or oil, gas or refined oil. Thus, oil, gas and refined oil are more inter-substitutable than with coal and, finally, electricity. Values of the elasticities of substitutions were chosen in line with the literature: electricity-fossil fuel substitution is based on Paltsev et al. (2005), the other two elasticities are from Burniaux and Truong (2002). ${ }^{3}$ Finally, the value of the energy aggregate is subject to the efficiency improvements projected by the growth model. As stressed above, in CGE models $\mathrm{CO}_{2}$ emissions and

\footnotetext{
3 In order to avoid unrealistic results, we assume 'constant energy technology' in non-electricity energy production sectors (coal, oil, gas, petroleum, coal products): it is impossible to produce crude oil from coal, or refined petroleum from gas and electricity. In these sectors, substitutions between energy sources are not allowed (Leontief formulation).
} 
energy consumption in physical quantities compared to variables measured in dollars at constant prices, present a challenge. In practice, using CES functional forms with variables in monetary units leads to inconsistencies when trying to retrieve physical quantities. In addition to the accounting relations in constant dollars, MIRAGE-e integrates a parallel accounting in energy physical quantities (in million tons of oil-equivalent) based on the use of two country- and energy-specific endogenous adjustment coefficients, such that $\mathrm{CO}_{2}$ emissions can be computed in millions of tons of $\mathrm{CO}_{2}$. Carbon dioxide emissions are recovered as proportional to energy consumption in quantity, using energy-, sector- and country-specific parameters calibrated on the data.

Production factors in MIRAGE-e are evolving, in yearly steps, as follows. Population and participation in the labor market evolve in each country (or region of the world economy) according to the demographics used in MaGE. This determines the labor force as well as its skill composition (skilled, unskilled). Primary resources and land are considered at their 2004 level: prices adjust demand to this supply. Instead of modeling the fossil energy sectors, we rely on the more specialized modeling of the International Energy Agency (IEA, 2011), which provides us with projections for coal, oil and gas prices up to 2035. Given demand, resources adjust accordingly in MIRAGE. Capital is accumulated according to the usual permanent inventory assumption. Capital usage is fixed (we use a $6 \%$ depletion rate), while gross investment is determined by the combination of saving (the saving rate from MaGE applied to the national income) and comparison of the current account and domestic absorption. Finally, while total investment is saving-driven, its allocation is determined by the rate of return on investment in the various activities. For simplicity, and because we lack reliable data on Foreign Direct Investment (FDI) at country of origin, host and sectoral level, we allow capital flows between regions only through the channel of current account imbalances. We are aware that FDI is channeling technology transfer and productivity catch-up; this mechanism will be integrated separately when building the scenarios.

Firms' demand for production factors is organized as a CES aggregation of land, natural resources, unskilled labor, and a bundle of the remaining factors. This bundle is a CES aggregate of skilled labor, and another bundle of capital and energy. Finally, energy is an aggregation of energy sources as defined above.

On the demand side, a representative consumer from each region maximizes its intra-temporal utility function under its budget constraint. This agent, which could be a household or government, saves a part of its income. This behavior is determined by the saving rate projected by the growth model on the basis of combining individual countries' demographic profiles with a life-cycle hypothesis. Expenditure is allocated to commodities and services according to a LES-CES (Linear Expenditure System - Constant Elasticity of Substitution) function. This assumption means that, above a minimum consumption at sectoral level, consumption choices between sectors are according to a CES. This assumption is a tractable representation of the preferences in countries at different levels of development. Thus, it is well suited to our purpose.

Then, within each sector, goods are differentiated by their origin. A nested CES function allows for a particular status for domestic products according to the usual Armington hypothesis (Armington, 1969). We use elasticities provided by the GTAP database (Global Trade Analysis Project) and estimated by Hertel et al. (2007). Total demand is built from final consumption, intermediate consumption and investment in capital goods.

Efficiency in the use of primary factors and intermediate inputs is based on the combination of four mechanisms. First, agricultural productivity is projected separately, as detailed in Fontagné et al. (2013). Second, energy efficiency computed by MaGE is imposed on MIRAGE (it enters the capitalenergy bundle). Third, a 2 percentage point growth difference between TFP in manufactures and services is assumed (as in van den Mensbrugghe, 2006). Fourth, given the agricultural productivity 
and the relation between productivity in goods and services, MIRAGE-e is able to recover endogenously country specific TFP from the exogenous GDP (from MaGE) and production factors. While this TFP is recovered from the pre-experiment, it is set as exogenous in the simulations of the scenarios, as explained later. Dynamics in MIRAGE-e is implemented in a sequentially recursive approach. That is, the equilibrium can be solved successively for each period by adjusting to the growth in the projected variables described above. For this long-run baseline, the time span is 31 years, the starting point being 2004.

Feeding the world population and providing the industry with its agro-related primary resources will be continuing challenges in future decades. It is therefore essential to properly assess to what extent technical progress in the agricultural sector will mitigate these problems. Whereas data on labour-force in agriculture are available, there are no aggregated data on capital in agriculture, although there are some disaggregated data (machinery, land, etc.). We need to implement a multi-input, non-parametric methodology, such as the Malmquist productivity index, based on productivity distance to a global (moving) frontier (for details, see Fontagné et al., 2013). We use FAO data for agricultural production and inputs. We chose two agricultural outputs (crops and livestock) and, on the basis of their common occurrence across the world, and data availability, five inputs (labor, land, machinery, fertilizers, livestock). Inputs can be allocated either to crops or to livestock, or be shared between these sectors.

Table 1 - Sector and country aggregation in MIRAGE

\begin{tabular}{|c|c|}
\hline Regions & Sectors \\
\hline Developed countries & Agriculture \\
\hline EU27 & Crops \\
\hline European Free Trade Association & Livestock \\
\hline USA & Other Agriculture \\
\hline Canada & Energy \\
\hline Japan & Coal \\
\hline \multirow[t]{2}{*}{ Australian and New Zealand } & Oil \\
\hline & Gas \\
\hline Developing/Emerging countries & Petroleum and coal products \\
\hline Brazil & Electricity \\
\hline Russia & Industry \\
\hline India & Food \\
\hline China & Textile \\
\hline Korea & Metals \\
\hline Association of Southeast Asian Nations & Cars and Trucks \\
\hline Middle-East & Transport equipment \\
\hline Turkey & Electronic devices \\
\hline North Africa & Machinery \\
\hline South Africa & Other Manufacturing \\
\hline Mexico & Services \\
\hline Rest of Africa & Transport \\
\hline Rest of Europe & Finance, Insurance and Business services \\
\hline Rest of Latin America & Public administration \\
\hline Rest of the world & Other services \\
\hline
\end{tabular}

MIRAGE-e was calibrated on the GTAP dataset version 7, with 2004 as base year. Our data aggregation isolates all energy sectors and combines other sectors into main representative sectors in agriculture, manufacturing and services. For the regional aggregation, we retained the main developed (e.g. EU, Japan and the US) and emerging (e.g. Brazil, Russia, China) economies, aggregated with the 
rest of the world on a geographical basis (see Table 1). We include international transaction costs and non-tariff measures (NTM) in services, modeled as an iceberg trade cost. Data to calibrate trade costs associated with time were calibrated using a database provided by Minor and Tsigas (2008), which adopts the methodology in Hummels and Schaur (2012); NTM in services are ad-valorem equivalents taken from Fontagné et al. (2011).

\subsection{The dynamic baseline calibration}

A difficulty related to large scale CGE models is whether the main stylized facts of world trade can be reproduced easily using this framework. Similar to the well-documented magnified reaction of world trade to booms and busts in the world economy (see Figure 1), the exercise is hopeless. CGE represent long term equilibrium, and cannot reproduce short term adjustments.

More importantly, we want our CGE to reproduce the medium term income elasticity of trade present in historical data. Table 2 shows trade income elasticity for different sub-periods.

Figure 1 - World trade-to-income elasticity of trade (goods)

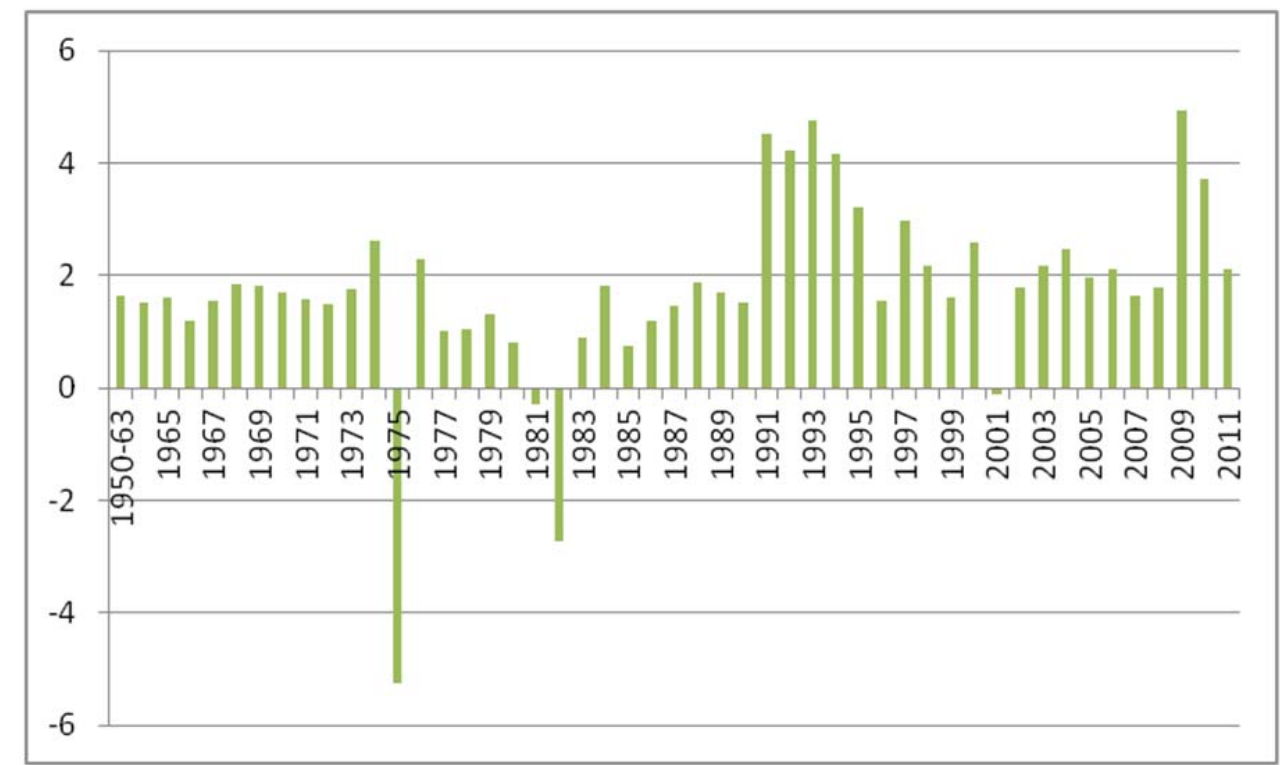

Source: Authors' calculation. WTO data 1950-2011.

Table 2 - World trade to income elasticity (goods), for different sub-periods

\begin{tabular}{ccccccc}
\hline $1950-59$ & $1960-69$ & $1970-79$ & $1980-89$ & $1990-99$ & $2000-09$ & $1950-2009$ \\
\hline 1.62 & 1.54 & 1.31 & 1.19 & 2.82 & 1.42 & 1.64
\end{tabular}

Source: Authors calculation. WTO data 1050-2011.

The 1990s have been documented as conveying an increase in this elasticity (Freund, 2009, partly because value chains have been fragmented globally and partly because the contributors to world economic growth chose export-oriented growth (e.g. China). We can hardly assume that the phenomenon will continue with the same intensity in the forthcoming two decades because there is a physical limit to product fragmentation and because complexity costs are increasing while the opportunities for exploiting new comparative advantages are most exhausted. 
In a much longer perspective, trade in goods since 1950 has increased faster than industrial or agricultural production, and even more than GDP. Long-term elasticity with respect to GDP was 1.46 over the period 1950-1989, before the rapid growth in world trade during the 1990s. This half-century experience is of the order of magnitude that a model like MIRAGE should aim to reproduce. This elasticity mirrors increases in world trade that have several determinants:

- $\quad$ energy prices (and especially the oil price) have been decreasing since the 1970s;

- technological progress has occurred in the transport sector;

- $\quad$ tariffs have decreased over time;

- $\quad$ some non-tariff measures have been phased out;

- global value chains have been fragmented, leading to increased discrepancy between trade measured in gross terms, and GDP measured as value added terms.

Therefore, using MIRAGE-e, we develop two baselines in order to encompass elasticity of world trade in goods (and manufacturing goods in particular). The first, 'Past Trade' tries to reproduce historical evidence; 'Pre-experiment' adjusts the model in order to start with a plausible elasticity for the upcoming decades.

In order to test whether MIRAGE-e can reproduce historical evidence, we first implement a sensitivity reference case ('Past Trade') using different sets of assumptions. The basic case is the standard version of the model with no changes in transaction costs. Tariffs are kept constant. There is no TFP growth in the transport sector beyond what is endogenously determined by the model to match growth projections from MaGE, as referred to above. There is no change in trade costs, which are kept at their initial (2004) level. Energy prices are taken from the central scenario already discussed. We run the model over 30 years and compute the trade to income elasticity.

Results reported in Table 3 show that the trade-to-income elasticity embodied in MIRAGE-e is low, as usual for any model of this type: 1.22 (first row in Table 3). This elasticity matches what was observed during the 1980s.

In order to reproduce the higher elasticity observed in the 1950s and 1960s, shown in the middle of panel in Table 3, we integrate a combination of decreasing trade costs, progress in transport technologies, low energy prices and trade liberalization, based on the following assumptions which reproduce the above mentioned determinants of long term income trade elasticity:

- very low energy prices (decreasing by 3\% yearly for oil, and no growth for coal and gas, according to the 1980-2004 average from BP historical data);

- $2 \%$ additional TFP growth in the transport sector compared to other services (containerization, standards, etc.), in line with estimations of sectoral TFP differentials by Wolff (1999) for the period 1958-1987;

- $50 \%$ cut in trade costs in the broad sense (time, red-tape, quality of the communications, etc.), own guesstimate;

- $\quad 4 \%$ annual decrease in tariff rates (corresponding to the evolution of simple average tariffs between 1973 and 2004 in Deardorff and Stern, 1983). 
Table 3 - Long-term trade to income elasticity in MIRAGE-e under alternative assumptions

\begin{tabular}{|c|c|c|c|c|c|}
\hline \multirow[t]{2}{*}{ Baseline } & \multicolumn{4}{|c|}{ Assumptions on } & \multirow[t]{2}{*}{ Elasticity } \\
\hline & Energy prices & $\begin{array}{l}\text { TFP boost } \\
\text { in transport }\end{array}$ & Trade cost cut & Tariffs cuts & \\
\hline Standard & Ref & 0\% & $0 \%$ & $0 \%$ & 1.22 \\
\hline Price & Decreasing & - & - & - & 1.33 \\
\hline TFP transport & - & $4 \%$ & - & - & 1.28 \\
\hline Trade cost & - & - & $50 \%$ & - & 1.37 \\
\hline Tariffs & - & - & - & $4 \%$ annual & 1.32 \\
\hline Past trade & Decreasing & $4 \%$ & $50 \%$ & $4 \%$ annual & 1.65 \\
\hline TFP transport & - & $2 \%$ & - & - & 1.27 \\
\hline Trade cost & - & - & $25 \%$ & - & 1.29 \\
\hline Pre-experiment & Ref & $2 \%$ & $25 \%$ & $0 \%$ & 1.34 \\
\hline
\end{tabular}

Note: All the scenarios are implemented between 2004 and 2035, linearly (trade costs) or at constant growth rate (TFP and decreasing energy price).

Source: MIRAGE, author's calculations.

The elasticity observed in the 1970s can be reproduced only by introducing in the model the observed tariff cuts. No additional assumption is required about transport technologies or trade costs. Indeed, the assumption of low energy prices is irrelevant for that period.

The elasticity observed in the 2000s can be nearly matched with a (large) drop in trade costs. ${ }^{4}$ We alternatively introduce large TFP gains in the transportation sector or even a decreasing price for energy.

Finally, what this kind of model cannot reproduce with plausible assumptions, is the trade to income elasticity observed in the 1990s; as already stressed, this period might be unique and it should not be reproduced in the baseline used for projections for future decades.

Regarding our reference scenario, we believe that many of the conditions of the $20^{\text {th }}$ century that lead to such high elasticity of trade to GDP will not be reproduced in upcoming decades, in particular those regarding energy prices. For this reason, we implement a pre-experiment with the following assumptions:

- $\quad 2 \%$ additional TFP growth in transport sector;

- $\quad 25 \%$ trade cost cuts;

- reference energy prices;

- $\quad$ no tariff cut.

As the decomposition shows, the boost in TFP for the transport sector and the drop in trade costs have effects of similar magnitude. When combining these assumptions, MIRAGE-e reproduces a long term elasticity of trade equal to 1.34, in line with what was observed in the 1970s and the 2000s. This pattern of MIRAGE-e, shown in the last row of Table 3, is the new reference which we will apply the scenarios described below.

4 Indeed, using a time span finishing in 2011 would give a higher elasticity. 


\subsection{Two scenarios for the world economy}

We next illustrate construction of the two contrasting scenarios that will be applied in a consistent way to the growth model - MaGE, and to the CGE of the world economy - MIRAGE-e. We first present the scenarios in MaGE, followed by their implementation in MIRAGE-e.

In order to design contrasting scenarios of the world economy, we combine various shocks with the aim of broadening the cone of possible trajectories, as follows. For simplicity, we refer to the resulting scenarios that combine these differentiated shocks, as 'low' and 'high', to describe the expected changes in world GDP.

For the low and high scenarios, we assume changes in education attainment, female participation in the labor market, and energy prices that apply homogenously across countries. In contrast, high income-countries, as opposed to low- and middle-income countries, are affected differently by changes in fertility, migration, energy efficiency, TFP and capital mobility. ${ }^{5}$ The shocks imposed on MaGE in a first step are reported in Table 4.

The first variable to experience a shock is demography. We start from the UN's low and high fertility scenarios. The low case is defined as lower fertility in middle- and low-income countries. This will have a negative impact on growth, although not necessarily on income per capita. We do not assume any reduction in fertility in high-income countries. Symmetrically, the high case corresponds to higher fertility in the middle- and low-income economies only. In certain developed countries it is possible that an unexpected rebound in fertility will be observed, but this outcome cannot be considered a general pattern.

The second variable of interest is migration. There are some migration flows embedded in the UN's demographic projections. These correspond to the 'normal migration assumption' where net migration is generally kept constant, at least for our time horizon. The UN introduces changes on a country by country basis, corresponding to anticipated immigration policy changes, and the imposed shock enhances these flows. We consider migration from Sub-Saharan Africa (SSA), and the Middle-East and North Africa (MENA) to Europe, and from Latin America to the US. First, annual additional outflows to Europe amount to 1.2 million people from SSA and 800,000 from MENA. This corresponds roughly to a doubling of net migration to Europe, compared to UN data for the period 2000-2010. Second, migration from Latin America to the US is 1.2 million persons per year, which is double North America's net inflow. We were not able to trace UN projected migrations precisely (by sex, age group or education level). Therefore, the initial migrants in UN projections, who are present in all scenarios, are assumed to resemble the local inhabitants. Additional migrants in the high case belong to the working-age population (15 to 64), and are divided across age groups and gender proportional to the shares of these categories in the population of the country of origin; they are assumed to maintain their initial level of education. Only in relation to life expectancy do the additional migrants mimic the host country natives.

We also address the impact of accelerated or decelerated convergence in education. In MaGE, catch up to the education frontier plays an important role because it drives convergence in TFP. The productivity frontier is not constant because the leading country (which can change over time) is continuously improving its education level. For each region of the world, we estimated in MaGE the

\footnotetext{
5 In MaGE, countries are classified by income level, which drives conditional convergence. Our shocks are defined using the World Bank income classification. For the presentation of the results and the simulations with MIRAGE, we use the WTO country group classification of developed and developing. The correspondence between the two classifications is provided in Appendix B.
} 
structural speed of convergence to the education frontier. We consider the half-life time ${ }^{6}$ for this process and increase it by $50 \%$ in the low case. We expect this to reduce technological catch-up and hamper growth. Alternatively, we divide by two the estimated half-time in order to take account of acceleration in the accumulation of human capital in middle- and low-income countries.

Table 4 - Shocks to MaGE

\begin{tabular}{|c|c|c|}
\hline Variable \Scenario & Low & High \\
\hline $\begin{array}{l}\text { Differentiated } \\
\text { demography }\end{array}$ & $\begin{array}{l}\text { Reference fertility in high income } \\
\text { countries, low fertility in other }\end{array}$ & $\begin{array}{l}\text { Reference fertility in high-income } \\
\text { countries, high fertility in other } \\
\text { countries }\end{array}$ \\
\hline Migrations & Reference case & $\begin{array}{l}\text { Additional migrations from SSA and } \\
\text { MENA to EU and from SAM to } \\
\text { USA/CAN. }\end{array}$ \\
\hline $\begin{array}{l}\text { Education } \\
\text { convergence }\end{array}$ & 1.5 half-life time & 0.5 half-life time \\
\hline Female participation & No improvements & Reference case \\
\hline Differentiated TFP & $\begin{array}{l}-50 \% \text { TFP growth rate for low and mid } \\
\text { income countries, }-25 \% \text { for high-income. }\end{array}$ & $\begin{array}{l}+50 \% \text { TFP growth rate for low and mid } \\
\text { income countries, }+25 \% \text { for high- } \\
\text { income. }\end{array}$ \\
\hline Energy price & High price scenario (EIA) & Low price scenario (EIA) \\
\hline $\begin{array}{l}\text { Differentiated Energy } \\
\text { productivity }\end{array}$ & $\begin{array}{l}+50 \% \text { high income in 2050, reference for } \\
\text { other }\end{array}$ & $\begin{array}{l}+50 \% \text { for low and mid income in } 2050 \text {, } \\
\text { reference for other }\end{array}$ \\
\hline Capital mobility & Convergence to $\mathrm{I}=\mathrm{S}$ in 2050 & $\begin{array}{l}\text { Low correlation coefficient (non- } \\
\text { OECD) for everyone }\end{array}$ \\
\hline
\end{tabular}

The fourth variable to be affected by a shock in MaGE is female labor market participation. In the low case we consider that the expected improvement in middle- and low-income economies, an additional driver of growth, will not occur for societal reasons. In the high case we keep this improvement as in the reference case.

The fifth variable of interest is TFP. As already explained, TFP is endogenous in MaGE. It is determined by a catching up process in which distance to the technology frontier and education drive convergence. We add an exogenous gain or loss of TFP respectively in the high and low cases, but otherwise the process is kept unchanged. There will be a TFP gain as a result of additional technology transfer via FDI, exports (e.g. via contracts related to utilities, armament, power generation) or collaborative research. The TFP growth rate will increase with larger benefits for catching up countries with higher initial TFP growth rates. In contrast, in the low case, a deteriorating economic environment will produce the opposite evolution, which will be topped by capital destruction, and long term unemployment. Again the impact will be greater for catching up countries, and will have a detrimental effect on their growth rates. TFP shocks correspond to previously observed episodes. Figure 2 shows that, during the past 30 years, there have been many periods and many countries when TFP growth has slowed or become negative, or alternatively experienced buoyancy. The most notable include the transition of Russia after the fall of the USSR, and Japan during the 1990s. Our scenarios try to consider the impact of similar prolonged phases that are not captured by econometric estimation. The mechanisms described above (FDI, technology transfer, collaborative research) are topped by an overall technological boost in the high case, leading to a 50\% increase in TFP for middle- and low-

\footnotetext{
6 Half-life time is defined as the time necessary to reduce by half the distance to the education frontier, assuming a constant frontier.
} 
income countries, and a $25 \%$ increase for high income economies only. Everyone is better off, but the technological leadership of high-income countries is eroded. The low case reflects 'hard times' when limited TFP gains in the North (just three-quarter of the gains projected in the reference scenario) lead to lower levels of technology transfer and tensions over intellectual property rights among this group of countries. As a result, TFP gains are even more reduced (-50\%) in the group of catching-up countries. This is a less cooperative world in which everyone is worse off, but where the richest countries preserve part of their initial advantage.

Figure 2 - Level of TFP and TFP leaders, 1980-2009

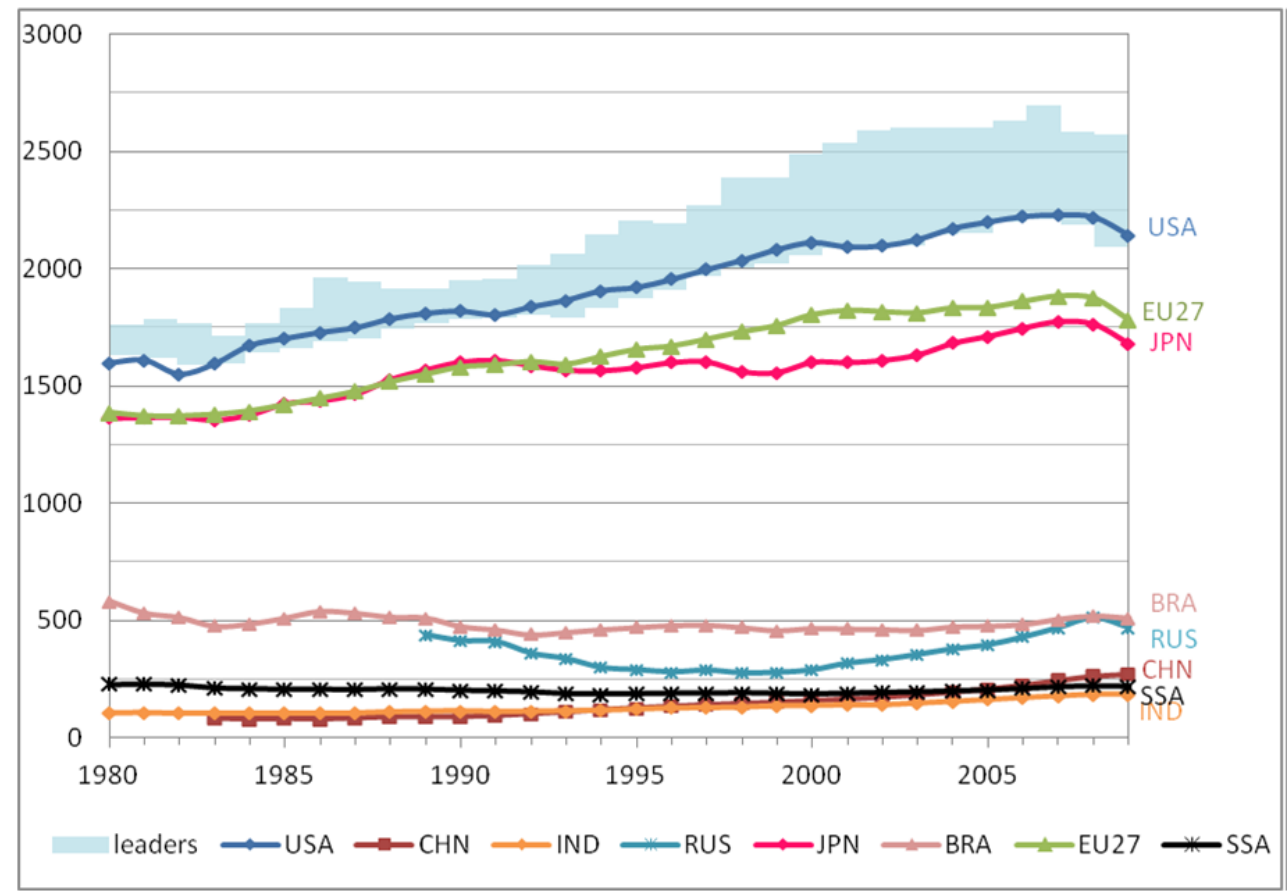

Notes: TFP level is corrected for oil rents bias. Leader countries each year are the 5 countries with highest TFP, excluding Luxemburg. These countries include the USA, Denmark, Sweden, Ireland, Belgium, France, the Netherlands and Germany, depending on the year considered.

Source: MaGE, authors' calculation.

Another variable of interest is national energy efficiency. Technological breakthroughs could have a major impact on energy efficiency, since sectoral transition to less energy-intensive activities is endogenous, monitored by the conditionality of catching-up in energy productivity to GDP per capita, as depicted in Figure 3 for the MaGE reference case. Here, we assume that countries at different levels of development will benefit unevenly from this progression. In the low case, technical progress occurs in the high income countries, but is not passed on to the middle- and low-income ones. Efficiency gains in energy accordingly are concentrated in the already most efficient countries (we assume a 50\% increase with respect to the reference scenario), with lower impact on the overall energy efficiency of the world economy. In the high case efficiency gains are concentrated in the middle- and low-income countries, based on the assumption of increased transfers of the existing technology.

\footnotetext{
7 At the beginning of projections, almost every country had passed the turning point between efficiency decrease and improvement.
} 
Figure 3 - Energy intensity of the GDP in the reference scenario of MaGE, 1980-2035 (barrel of oil per 1,000 2005 USD of GDP)

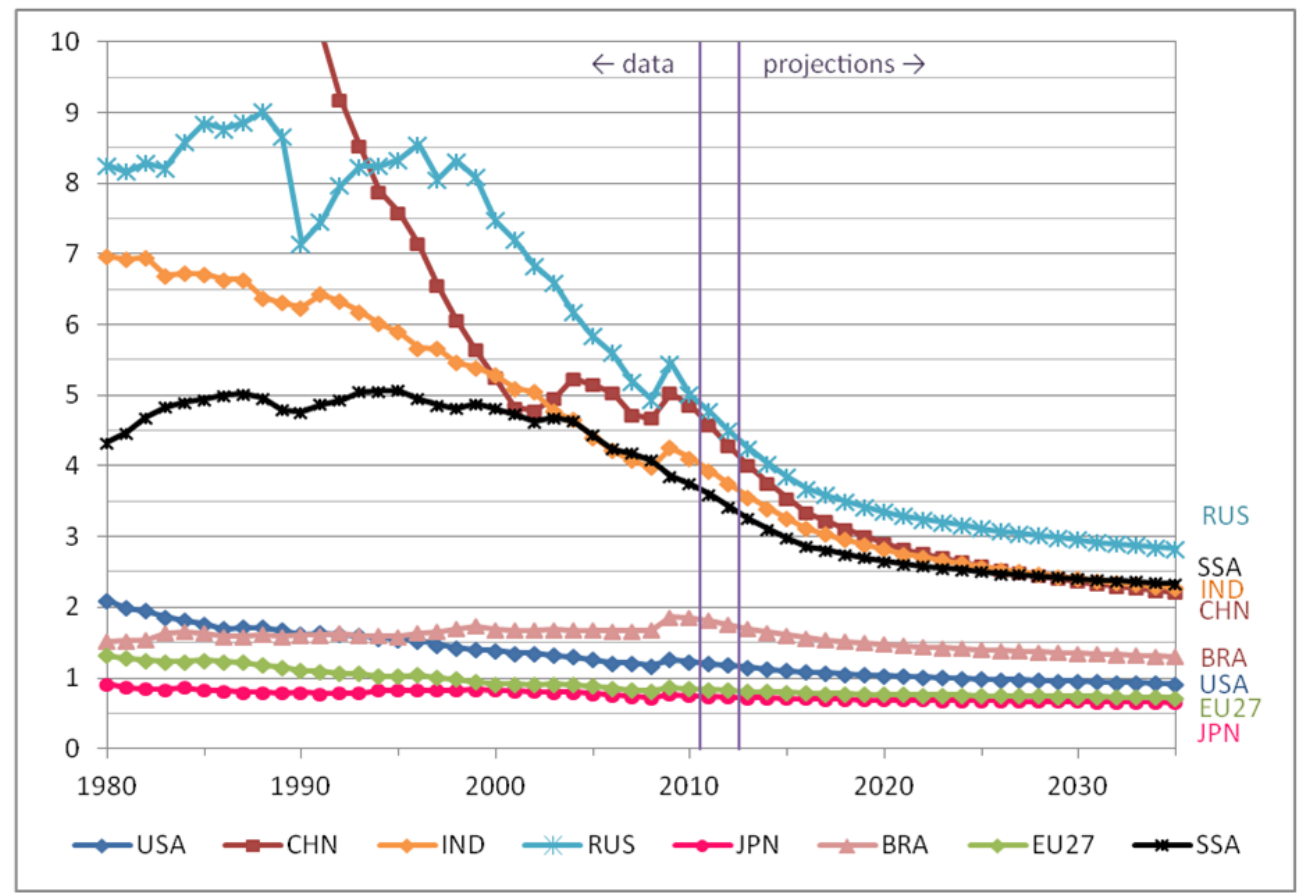

Source: MaGE, authors' calculation.

Figure 4 - Saving-Investment balance in the reference scenario, 1980-2035 (percentage of GDP)

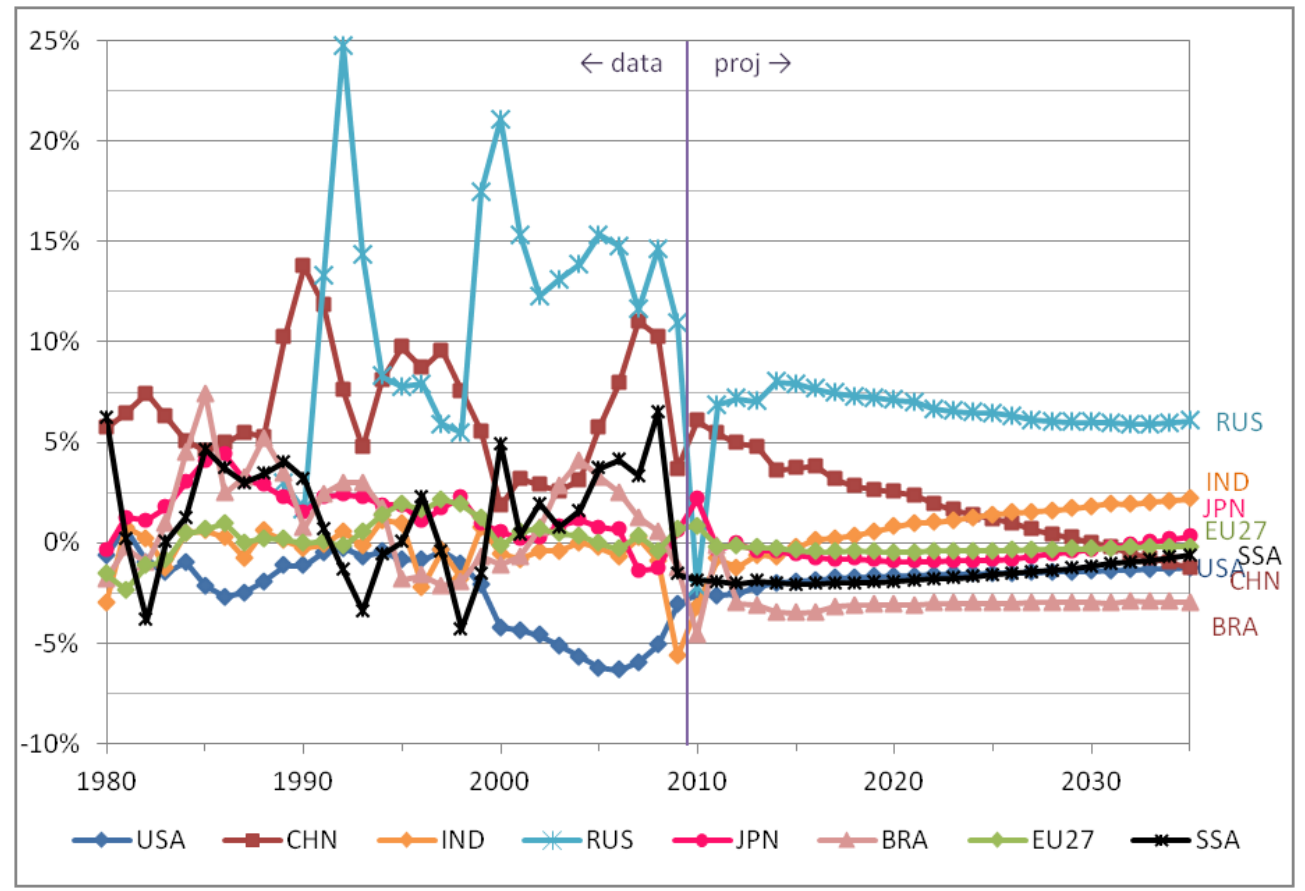

Source: MaGE, authors' calculation. 
Finally, capital mobility is an important determinant of growth since it shapes the difference between national saving and investment. Increased capital mobility should allow better allocation of capital worldwide and, thus, enhance growth overall. In the high case, we align the correlation between domestic saving and investment at world level with the lowest regional level, which is the one of the non-OECD countries. Note that this choice leads to no gain in capital mobility for the latter group of countries. However, in the low case, there is 'financial de-globalization', meaning that countries return progressively to financial autarky by 2050 (beyond the horizon of this exercise: thus, not achieved at the 2035 horizon).

Notice that assumptions about demographic profiles and capital mobility will modify the dynamics of the saving-investment balance depicted in Figure 4, characterized by a natural rebalancing of the Chinese economy.

The next step is to use the results of these two scenarios imposed on MaGE as inputs for MIRAGE. This provides two baselines that will experience additional shocks to the variables not included in MaGE (e.g. sectoral value added) and will become 'High Sim' and 'Low sim'. For each scenario we compute the baseline scenario in MIRAGE on which we impose GDP, population, total labour force, skill level, saving, energy productivity, agricultural productivity, current account and energy price. We reproduce global trends in transaction costs consistent with the observed income elasticity of international trade (as already discussed) and recover TFP. As the energy price is exogenous, natural resources adjust endogenously at the baseline. Our two baselines assume status quo for tariffs as well as non-tariff barriers. We ultimately establish high and low for MIRAGE, which we call 'High Ref' and 'Low Ref' respectively (Table 5).

Table 5 - The two baselines of MIRAGE-e (2035 horizon)

\begin{tabular}{lll}
\hline & Low Ref & High Ref \\
\hline MaGE scenario & Low & High \\
Energy prices & High price & Low price scenario \\
Transaction costs for goods $^{*}$ & $25 \%$ cut & $25 \%$ cut \\
Transports TFP $^{*}$ & 2\% annual growth & 2\% annual growth \\
Tariffs & No change wrt 2007 & No change wrt 2007 \\
\hline
\end{tabular}

*As discussed in the text, these two trends were introduced in a pre-experiment in order to reproduce long-term income elasticity of world trade.

The final step consists of implementing trade scenarios in each of the two baselines (tariffs, transaction costs and NTM in services) with GDP and energy price set to be endogenous (TFP and natural resources fixed at their baseline level). These scenarios are summarized in Table 6. In the 'Low sim' scenario an increase in transaction costs and tariff is applied to the low baseline. The 'High sim' scenario starts from a high baseline and describes a more cooperative world where the barriers to trade in goods and services are reduced compared to their 2007 level.

In the 'Low Sim' scenario, we impose on the 'Low Ref' baseline a series of shocks reproducing an increase in transaction costs and a tariff war. In the context of a low growth profile and, possibly, geopolitical tensions, countries increase bureaucracy at the border, and systematize container scanning. Developing countries are more affected by this since their exports are perceived as 'unsafe' by the advanced economies. This degradation of the world trading environment is progressive: we add a 20\% increase in the transaction costs for developed countries' exports, linearly over the period considered (2014-2035). The increase peaks at 50\% for developing countries' exports. The second dimension to this degradation of the trading environment refers to protectionism. Countries either 
respect de jure WTO commitments and rely almost exclusively on anti-dumping duties and safeguards, or revert to using their bound tariffs, or contribute to the non-cooperative scenario in which earlier commitments cease to be respected. To reproduce this outcome, we assume a progressive return of the world economy to post-Tokyo Round levels of protection, over the two decades considered. This is implemented as follows.

Table 6 - The two scenarios implemented in MIRAGE-e (2035 horizon)

\begin{tabular}{lll}
\hline & Low Sim & High Sim \\
\hline Applied to baseline & Low Ref & High Ref \\
Transaction costs for & $+50 \%$ from developing countries & $-50 \%$ from developing countries \\
goods & $+20 \%$ from developed countries & $-20 \%$ from developed \\
Tariffs on goods & $\begin{array}{l}\text { Trade war scenario (Tokyo round } \\
\text { tariffs) }\end{array}$ & $-50 \%$ compared to 2004 \\
NTM in services & No change & Liberalization in services (-50\%) \\
\hline
\end{tabular}

For manufacturing, we try to reproduce post-Tokyo Round tariffs. We use available data from Deardorff and Stern (1983) by sector. For aggregated regions, we adopt a simple average. For the rest, we take the oldest data from the World Development Indicators (WDI) to which we add a 25\% increase. For the agro-food sector, we simply reverse the Uruguay round (Agreement on Agriculture) and add 36\% to developed countries' tariffs and 24\% to those of developing countries; for energy goods, we keep tariffs constant. Tariffs within Free Trade Areas (FTAs) are assumed not to be subject to a tariff war and are not increased in our scenario. This affects the EU27, EFTA, NAFTA, AU-NZ and USA-AUNZ. These tariff increases provide a target for 2030, which we implement linearly between 2013 and 2030. Tariffs are constant after 2030. We present this procedure in Table 7 for selected sectors.

The high scenario ('High sim') describes a more cooperative world. Firstly, tariffs on goods are reduced (-50\%) compared to their 2007 level. Secondly, benefiting from sustained growth and rapid convergence of emerging countries (increasing income levels and reducing costs of competition), countries address the issue of trade in services. There is a large decrease in the barriers to trade in services, and transaction costs on goods continue to decrease and decrease faster for developing countries where progress margins are bigger. We assume a 50\% decrease in transaction costs for developing countries and a $20 \%$ decrease for developed countries. ${ }^{9}$ Regarding the reduction in the barriers to trade in services, we start with the ad valorem equivalents computed by Fontagné et al. (2011), modeled here as a trade cost. We then set the target to $-50 \%$ in 2030, and this phasing out is implemented linearly between 2013 and 2030. The outcome of this exercise is shown in Table 8.

Finally, the overall three-step method is summarized in Figure 5.

\footnotetext{
8 This methodology implies that targeted tariffs may be lower than or equal to the 2004 tariff in GTAP. For primary products, tariffs are not available in Deardorff and Stern and we use 2004 levels. For 252 triplets out of 9,261 this situation occurs as a result of averaging bias (sectors where the tariff decreased to less than the average value) or to aggregation bias (our simple average does not match the GTAP weighted average).

9 Recall that the impact of energy prices on demand for transport is taken into account endogenously in MIRAGE-e.
} 
Table 7 - Tariff scenario by importer for selected sectors, 'Low Sim' versus 'Ref'

\begin{tabular}{|c|c|c|c|c|c|c|c|c|c|c|}
\hline \multirow{2}{*}{$\begin{array}{c}\text { Sector } \\
\text { Scenario } \\
\text { Importer }\end{array}$} & \multicolumn{2}{|c|}{$\begin{array}{l}\text { Cars and Trucks } \\
\text { (Manuf.) }\end{array}$} & \multicolumn{2}{|c|}{$\begin{array}{l}\text { Primary } \\
\text { (Manuf.) }\end{array}$} & \multicolumn{2}{|c|}{$\begin{array}{l}\text { Coal } \\
\text { (Energy) }\end{array}$} & \multicolumn{2}{|c|}{$\begin{array}{l}\text { Crops } \\
\text { (Agro-Food) }\end{array}$} & \multicolumn{2}{|c|}{$\begin{array}{l}\text { Food } \\
\text { (Agro-Food) }\end{array}$} \\
\hline & Ref & $\begin{array}{l}\text { Low } \\
\text { Sim }\end{array}$ & Ref & $\begin{array}{r}\text { Low } \\
\text { Sim }\end{array}$ & Ref & $\begin{array}{l}\text { Low } \\
\text { Sim }\end{array}$ & Ref & $\begin{array}{l}\text { Low } \\
\text { Sim }\end{array}$ & Ref & $\begin{array}{l}\text { Low } \\
\text { Sim }\end{array}$ \\
\hline ASEAN & 19.2 & 21.5 & 2.1 & 16.2 & 1.3 & 1.3 & 10.0 & 12.3 & 20.3 & 24.0 \\
\hline AUNZ & 6.4 & 24.0 & 0.3 & 0.3 & & & 0.5 & 0.6 & 3.0 & 3.0 \\
\hline Brazil & 14.0 & 45.2 & 3.1 & 45.2 & & & 7.0 & 8.7 & 10.8 & 45.2 \\
\hline Canada & 3.0 & 3.4 & 0.1 & 0.1 & & & 0.7 & 0.9 & 10.3 & 10.3 \\
\hline China & 17.2 & 43.3 & 1.2 & 43.3 & 3.5 & 3.5 & 6.4 & 8.0 & 10.5 & 43.3 \\
\hline EFTA & 0.5 & 5.1 & 4.7 & 4.7 & 0.2 & 0.2 & 26.0 & 35.1 & 40.2 & 40.2 \\
\hline EU27 & 3.2 & 10.5 & 0.1 & 0.1 & 0.0 & 0.0 & 8.8 & 11.9 & 15.8 & 15.8 \\
\hline India & 19.3 & 90.8 & 9.0 & 90.8 & 23.8 & 23.8 & 29.0 & 35.9 & 49.6 & 91.6 \\
\hline Japan & 0.0 & 5.7 & 0.3 & 0.3 & 0.0 & 0.0 & 9.5 & 12.9 & 20.3 & 20.3 \\
\hline Korea & 7.3 & 20.1 & 1.6 & 20.1 & 0.9 & 0.9 & 43.1 & 53.5 & 25.2 & 27.8 \\
\hline Mexico & 14.6 & 17.6 & 8.6 & 15.4 & 5.1 & 5.1 & 8.1 & 10.0 & 16.4 & 18.1 \\
\hline Middle East & 10.5 & 31.6 & 2.7 & 30.7 & 2.6 & 2.6 & 11.2 & 13.8 & 15.5 & 32.4 \\
\hline North Africa & 19.5 & 32.2 & 6.7 & 31.0 & 7.5 & 7.5 & 19.1 & 23.4 & 18.7 & 31.5 \\
\hline Rest of Africa & 13.1 & 16.3 & 5.7 & 16.1 & 3.3 & 3.3 & 11.1 & 13.7 & 16.9 & 18.5 \\
\hline Rest of Europe & 5.0 & 10.9 & 1.6 & 10.7 & 0.4 & 0.4 & 9.4 & 11.6 & 21.8 & 21.9 \\
\hline Latin America & 14.2 & 18.8 & 3.8 & 17.4 & 1.9 & 1.9 & 7.9 & 9.8 & 16.3 & 18.6 \\
\hline $\begin{array}{l}\text { Rest of the } \\
\text { World }\end{array}$ & 16.3 & 19.4 & 2.4 & 16.2 & 1.8 & 1.8 & 9.7 & 12.0 & 18.7 & 22.6 \\
\hline Russia & 9.9 & 11.7 & 4.3 & 9.0 & 3.8 & 3.8 & 5.9 & 7.3 & 14.3 & 15.2 \\
\hline South Africa & 15.3 & 17.4 & 0.3 & 16.0 & & & 6.1 & 7.5 & 14.0 & 19.6 \\
\hline Turkey & 5.7 & 7.3 & 0.4 & 6.4 & & & 20.1 & 24.9 & 25.6 & 25.6 \\
\hline USA & 1.8 & 3.5 & 0.1 & 0.1 & & & 6.1 & 8.3 & 5.4 & 5.4 \\
\hline Total & 10.4 & 22.0 & 3.0 & 20.5 & 4.9 & 4.9 & 12.2 & 15.4 & 18.6 & 26.3 \\
\hline
\end{tabular}

Note: Simple average. 'Ref' is the baseline tariff used for 'Low Ref' and 'High Ref'. 'Low Sim' is the scenario value.

Source: Authors' calculations based on GTAP, Deardorff and Stern (1983) and WDI. 
Table 8 - NTM tariff equivalent in services by importer

\begin{tabular}{|c|c|c|c|c|c|c|c|c|}
\hline \multirow{3}{*}{$\begin{array}{c}\text { Sector } \\
\text { Scenario } \\
\text { Importer } \\
\end{array}$} & \multicolumn{2}{|c|}{$\begin{array}{l}\text { Finance, Insurance, } \\
\text { Business serv. }\end{array}$} & \multicolumn{2}{|c|}{ Other Services } & \multicolumn{2}{|c|}{$\begin{array}{l}\text { Public } \\
\text { Administration }\end{array}$} & \multicolumn{2}{|c|}{ Transport } \\
\hline & & High & & High & & High & & High \\
\hline & Ref & Sim & Ref & Sim & Ref & Sim & Ref & Sim \\
\hline ASEAN & 44.2 & 22.1 & 48.0 & 24.0 & 34.4 & 17.2 & 26.6 & 13.3 \\
\hline AUNZ & 62.4 & 31.2 & 78.0 & 39.0 & 44.5 & 22.3 & 29.4 & 14.7 \\
\hline Brazil & 49.8 & 24.9 & 108.4 & 54.2 & 36.8 & 18.4 & 37.7 & 18.8 \\
\hline Canada & 31.0 & 15.5 & 56.5 & 28.2 & 35.9 & 18.0 & 27.1 & 13.5 \\
\hline China & 91.8 & 45.9 & 43.9 & 22.0 & 59.6 & 29.8 & 71.9 & 35.9 \\
\hline EFTA & 47.4 & 23.7 & 65.2 & 32.6 & 28.9 & 14.4 & 31.8 & 15.9 \\
\hline EU27 & 30.0 & 15.0 & 39.0 & 19.5 & 29.9 & 15.0 & 19.4 & 9.7 \\
\hline India & 105.5 & 52.7 & 103.6 & 51.8 & 68.4 & 34.2 & 51.3 & 25.6 \\
\hline Japan & 47.2 & 23.6 & 38.8 & 19.4 & 48.4 & 24.2 & 27.7 & 13.8 \\
\hline Korea & 40.8 & 20.4 & 71.7 & 35.9 & 36.2 & 18.1 & 13.4 & 6.7 \\
\hline Mexico & 56.5 & 28.2 & 65.1 & 32.5 & 38.9 & 19.5 & 36.0 & 18.0 \\
\hline Middle East & 68.0 & 34.0 & 72.2 & 36.1 & 46.8 & 23.4 & 48.0 & 24.0 \\
\hline North Africa & 55.4 & 27.7 & 70.9 & 35.4 & 38.0 & 19.0 & 43.5 & 21.8 \\
\hline Rest of Africa & 68.6 & 34.3 & 62.9 & 31.4 & 46.6 & 23.3 & 43.9 & 21.9 \\
\hline Rest of Europe & 63.7 & 31.8 & 76.2 & 38.1 & 48.7 & 24.3 & 42.8 & 21.4 \\
\hline Latin America & 65.5 & 32.8 & 77.2 & 38.6 & 39.3 & 19.7 & 32.6 & 16.3 \\
\hline $\begin{array}{l}\text { Rest of the } \\
\text { World }\end{array}$ & 44.7 & 22.4 & 53.6 & 26.8 & 27.6 & 13.8 & 22.2 & 11.1 \\
\hline Russia & 41.1 & 20.5 & 44.3 & 22.1 & 42.1 & 21.1 & 22.8 & 11.4 \\
\hline South Africa & 65.0 & 32.5 & 88.5 & 44.3 & 51.3 & 25.7 & 41.4 & 20.7 \\
\hline Turkey & 70.4 & 35.2 & 81.6 & 40.8 & 50.0 & 25.0 & 54.1 & 27.1 \\
\hline USA & 45.8 & 22.9 & 70.1 & 35.0 & 8.8 & 4.4 & 22.6 & 11.3 \\
\hline Total & 44.2 & 22.1 & 48.0 & 24.0 & 34.4 & 17.2 & 26.6 & 13.3 \\
\hline
\end{tabular}

Note: Simple average. Ref is the baseline level and 'High Sim' is the scenario values. Source: Authors' calculations based on Fontagné et al. (2011). 
Figure 5 - Design of scenarios in MaGE and MIRAGE

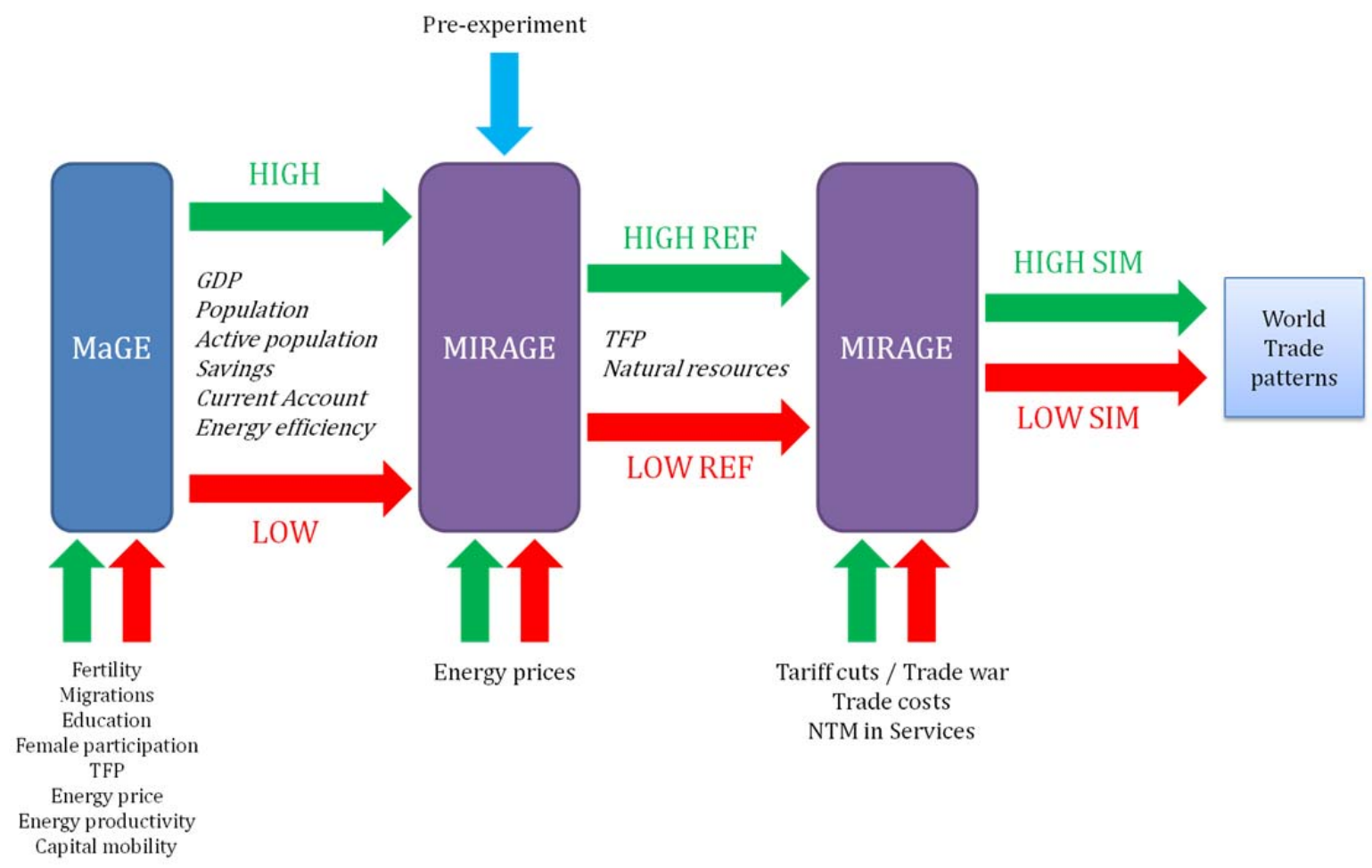




\section{IMPLEMENTING THE SCENARIOS IN MAGE}

We start by considering the impact of alternative assumptions regarding the variables of interest, shocked one at a time. We then consider the combination of differentiated shocks in the two scenarios.

\subsection{Demography and migration}

The demographic scenarios were defined as reference fertility for high income countries, and low fertility for other countries in the low scenario, versus reference fertility in high-income countries and high fertility in other countries in the high scenario.

The shock is quite symmetrical across the high and low scenarios, as shown in Table 9. Note that there are five EU member countries not classified by the World Bank as high income economies - Bulgaria, Lithuania, Latvia, Poland and Romania.

Table 9 - Differentiated population scenarios, 2035 (million people)

\begin{tabular}{lccc}
\hline & Ref & low & high \\
\hline United States of America & 373 & $+0.0 \%$ & $+0.0 \%$ \\
Japan & 117 & $+0.0 \%$ & $+0.0 \%$ \\
European Union & 513 & $-0.9 \%$ & $+0.9 \%$ \\
Brazil & 223 & $-7.8 \%$ & $+8.1 \%$ \\
Russian Federation & 134 & $-6.9 \%$ & $+7.0 \%$ \\
India & 1580 & $-7.5 \%$ & $+7.7 \%$ \\
China & 1382 & $-6.8 \%$ & $+6.9 \%$ \\
Latin America & 452 & $-7.6 \%$ & $+7.8 \%$ \\
Middle east and North Africa & 544 & $-6.6 \%$ & $+6.6 \%$ \\
Sub-Saharan Africa & 1320 & $-6.4 \%$ & $+6.4 \%$ \\
Rest of Asia & 1238 & $-7.2 \%$ & $+7.3 \%$ \\
Rest of the World & 193 & $-3.8 \%$ & $+3.9 \%$ \\
\hline Total world & 8068 & $-6.1 \%$ & $+6.2 \%$ \\
\hline
\end{tabular}

Source: MaGE, authors' calculation.

The next step for demography is to introduce migration (beyond the conservative migration flows included in the UN's demographic projections). In the low scenario, migration shows no change compared to our baseline projection. Thus, here we discuss only the high scenario. We assume annual migration outflow of $1,200,000$ people from SSA to the EU, migration of 800,000 from the MENA countries to the EU, and 1,200,000 people to the US from Latin America every year. Age, sex and education levels are the same for both destination and origin countries, but mortality and activity rates assume the levels of the destination country (although female labor force participation will be affected by the integration of migrants in the average education level computation). The results for population are presented in Table 10. Notice that total world population is affected because mortality is lower in the destination countries of migrants than in their countries of origin. 
Table 10 - Total population in the presence of additional migrations, 2035 (million people)

\begin{tabular}{lll}
\hline & Ref & high \\
\hline United States of America & 373 & $+6.6 \%$ \\
European Union & 513 & $+8.3 \%$ \\
Latin America & 452 & $-5.0 \%$ \\
Middle east and North Africa & 544 & $-2.4 \%$ \\
Sub-Saharan Africa & 1320 & $-1.8 \%$ \\
\hline Total world & 8068 & $+0.1 \%$ \\
\hline
\end{tabular}

Note: Other regions are not impacted by the migration scenario. Source: MaGE, authors' calculation.

As already noted, when migrants leave their origin country, their initial level of education remains unchanged. Given the numbers considered, migrants will have a significant impact on the share of the population at each education level. Table 11 shows the outcome of our assumptions related to education attainment at secondary and tertiary levels. Education increases in MENA and Latin America because of the age group aggregation. Due to different mortality rates among age groups and among countries within a country group, the drop in population numbers distorts the age structure across time (although migrants at time $t$ are equally distributed across age groups). Not surprisingly, origin countries have (on average) less human capital than destination countries and, therefore, immigrants work to reduce education levels, which explains the results for the EU and the US.

Table 11 - Secondary and tertiary education, 2035 (percentage of working-age population)

\begin{tabular}{|c|c|c|c|c|}
\hline & \multicolumn{2}{|l|}{ Secondary } & \multicolumn{2}{|l|}{ Tertiary } \\
\hline & Reference & high & Reference & high \\
\hline United States of America & 99 & -0.5 & 64 & -1.0 \\
\hline European Union & 93 & -1.5 & 38 & -1.4 \\
\hline Latin America & 74 & +0.2 & 25 & +0.1 \\
\hline Middle east and North Africa & 72 & +0.1 & 25 & +0.1 \\
\hline Total world & 71 & +0.3 & 20 & +0.3 \\
\hline
\end{tabular}

Note: Other regions are unaffected by the migration scenario.

Source: MaGE, authors' calculation.

The last direct consequence of the migration considered is for saving rates due to the distortion of the age structure (in both the origin and destination countries), which is the main determinant of saving in our life-cycle framework. Saving also determines investment capacity for a given level of international financial flows. Table 12 shows how the migrations scenarios affect investment and saving. 
Table 12 - Investment and saving rates, 2035 (percentage GDP)

\begin{tabular}{lrrrrr}
\hline & Investment & & & \multicolumn{2}{c}{ Saving } \\
\cline { 2 - 3 } \cline { 6 - 6 } & Reference & High & & Ref & High \\
\hline United States of America & 14 & +0.21 & & 13 & +0.34 \\
Japan & 21 & -0.11 & & 21 & -0.18 \\
European Union & 17 & +0.33 & & 16 & +0.56 \\
Brazil & 17 & -0.00 & & 14 & -0.03 \\
Russian Federation & 21 & -0.01 & & 27 & -0.06 \\
India & 20 & +0.00 & & 22 & -0.01 \\
China & 31 & -0.00 & & 30 & -0.04 \\
Latin America & 18 & -0.24 & & 18 & -0.65 \\
Middle east and North Africa & 20 & -0.11 & & 23 & -0.28 \\
Sub-Saharan Africa & 16 & -0.06 & & 16 & -0.30 \\
Rest of Asia & 22 & -0.04 & & 23 & -0.08 \\
Rest of the World & 19 & -0.10 & & 21 & -0.16 \\
\hline Total world & 20 & -0.08 & & 20 & -0.08 \\
\hline
\end{tabular}

Source: MaGE, authors' calculation.

The arrival of young age groups in ageing countries such as EU countries and the USA, tends to increase these countries saving rates $(+0.6 \%$ and $+0.3 \%$ of GDP, respectively). However, this is accompanied by a fall in saving rates in origin countries due to the departure of working-age population (but not younger and older people). At the global level, the saving loss is greater than the saving increase (-0.1\% of world GDP). Thus, the global investment envelope decreases while the share of EU and USA in this envelope increases and investment reduces in all other countries.

\subsection{Human capital accumulation and female participation}

In addition to demography, we need to investigate shocks to investment in human capital. Education catch-up over the past 50 years has been very diverse across regions and has been one of the main drivers of differences in per-capita income performance across countries. For estimation purposes, we estimate catch-up speed according to geographical regions. However, average speed does not encompass the diversity of situations depicted in Figure 6. Shocks to MaGE try to frame educational convergence and represent lower and upper bounds of catch-up using a standard catch-up measure: half-life time. Half-life time is the time it takes for a country to reduce its difference with the education leader by half, assuming a constant education frontier.

The increase in education levels observed for the emerging countries is shown in Figure 8, as the evolution in educational attainment in some Asian countries over the period 1980-2010. The pattern differs across countries. The achievements observed for Korea and Singapore fuelled productivity gains and helped to elevate income levels in those countries. By contrast, China remains at low levels, and its comparative advantage is mainly in low value added segments and low value added products.

In the high scenario, shown in Table 13, catch up is accelerated (50\% reduction in the half-life of convergence). Even assuming this investment in education is observed worldwide, its impact will be concentrated in countries far from the (moving) education frontier. In the USA and Japan, the increase in the percentage of the population completing tertiary education is respectively 3 and 2 percentage points. The impact is larger for the EU (+6 p.p.), due to the differentiated levels currently observed for member countries. The impact is also sizeable for Latin America (+7 p.p.). In China gains in relative 
terms are less important, though the absolute number of educated people is very large, which is important for world growth overall. China gains 4 percentage points for tertiary education and more than 1 percentage point for secondary education. However, most of the gains are concentrated on secondary education for the poorest countries (+8 p.p. in SSA). In India both levels benefit by 5 percentage points each. The low scenario shows symmetric results, although attenuated as a result of the assumption made (half-life increased by $50 \%$ ).

Figure 6 - Share of tertiary educated population in selected Asian countries, 1980-2010

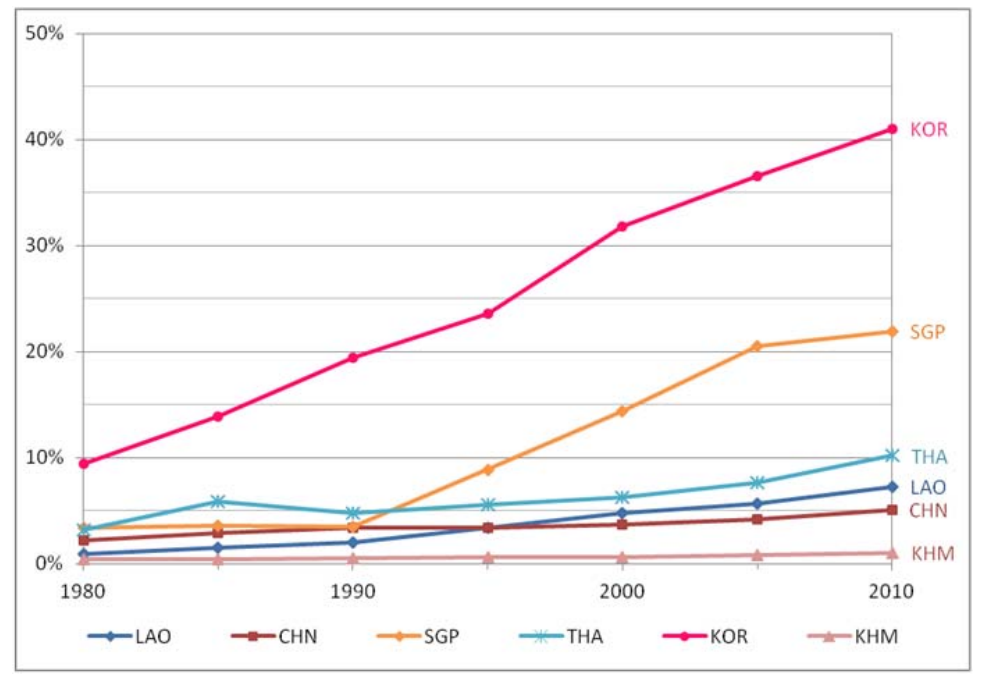

Key: $K O R=$ Korea, $S G P=$ Singapore, $T H A=$ Thailand, $L A O=$ Laos, $C H N=$ China, $K H M=$ Cambodia Source: Barro and Lee (2013).

Table 13 - Secondary and Tertiary education, 2035 (\% of population)

\begin{tabular}{|c|c|c|c|c|c|c|}
\hline & \multicolumn{3}{|l|}{ Secondary } & \multicolumn{3}{|l|}{ Tertiary } \\
\hline & Reference & low & high & Reference & low & high \\
\hline United States of America & 99 & -0.1 & +0.1 & 64 & -1.8 & +3.1 \\
\hline Japan & 97 & -0.1 & +0.2 & 64 & -1.3 & +2.2 \\
\hline European Union & 93 & -0.7 & +1.3 & 38 & -2.7 & +5.7 \\
\hline Brazil & 71 & -1.8 & +3.9 & 17 & -2.4 & +7.2 \\
\hline Russian Federation & 98 & -0.1 & +0.2 & 63 & -1.6 & +2.8 \\
\hline India & 66 & -2.3 & +5.2 & 12 & -1.5 & +5.2 \\
\hline China & 86 & -0.7 & +1.4 & 14 & -1.3 & +4.0 \\
\hline Latin America & 74 & -1.9 & +4.4 & 25 & -2.6 & +7.2 \\
\hline Middle east and North Africa & 72 & -2.1 & +4.4 & 25 & -2.6 & +6.9 \\
\hline Sub-Saharan Africa & 40 & -2.7 & +7.9 & 5 & -0.7 & +2.5 \\
\hline Rest of Asia & 62 & -2.5 & +5.8 & 17 & -1.4 & +4.3 \\
\hline Rest of the World & 94 & -0.7 & +1.2 & 46 & -2.8 & +5.4 \\
\hline Total world & 71 & -1.7 & +4.1 & 20 & -1.6 & +4.5 \\
\hline
\end{tabular}

Source: MaGE, authors' calculation. 
Another important labor market trend is female participation which ranges from $37 \%$ (India) to $54 \%$ (USA) to $57 \%$ (China). ${ }^{10}$ Any convergence in participation rates to the highest level will have an impact on the labor force and its skill composition. Two opposing effects compete. First, better educated women tend to participate more to the labor force. However, this is true only for women aged more than 25 years. For the younger age groups (15-19 and 20-24), longer studies work to decrease participation in the labor force. If the former (resp. latter) effect is greater, then the overall impact on labor force will be positive (resp. negative). In our baseline scenario, based on historical evidence we consider that there will be some form of convergence. We do not discuss a 'high' case which would mean women's participation increasing even more. Here, the high case is the same as the baseline. In the 'low' case, however, we constrain women's participation to be constant after 2010. This has an unexpected outcome for ageing economies where women's participation is expected to decrease naturally, for demographic reasons. By constraining this mechanism from applying in the future, the low scenario increases women's participation with respect to the reference scenario, for example, in Europe and Russia. The impacts of our scenario are shown in Table 14.

Table 14 - Female participation in the labour force, 2035 (percentage of female population)

\begin{tabular}{lrr}
\hline & Ref & low \\
\hline United States of America & 56 & -1.5 \\
Japan & 47 & -2.3 \\
European Union & 43 & +2.1 \\
Brazil & 54 & +5.5 \\
Russian Federation & 51 & +3.0 \\
India & 37 & -5.9 \\
China & 57 & -1.7 \\
Latin America & 46 & +3.9 \\
Middle east and North Africa & 30 & -4.3 \\
Sub-Saharan Africa & 63 & +1.7 \\
Rest of Asia & 50 & -0.8 \\
Rest of the World & 53 & +2.4 \\
\hline Total world & 49 & -1.1 \\
\hline
\end{tabular}

Source: MaGE, authors' calculation.

\subsection{Energy price and technical progress in energy use}

The next shock we consider is to energy prices, using EIA scenarios (Figure 7). It induces substitution and technical progress (although the link between the energy price and productivity is not integrated in our model), such that the energy intensity of GDP will be reduced in the case of high prices. Table 15 shows how this phenomenon cushions the impact of energy prices for different countries. The reference scenario is shown in column 1 , where values are energy intensity expressed as barrels of oil equivalent (boe) per US\$1,000 of GDP in 2035. Energy productivity can be observed independently, but does not include possible substitution for labor and capital. Thus, we present the results as energy intensity of GDP (E/Y). In general, lower productivity leads to higher energy intensity.

Columns 2 and 3 in Table 15 show changes in energy intensity measured in the same units. We observe first that the world economy is much more energy efficient under the high price scenario. For oil producing countries, this effect is reinforced by the oil rent boosting growth and facilitating

10 Female participation is highest in SSA (63\%). 
convergence in energy efficiency. The biggest gains are expected for SSA, and Russia. Japan, Europe and the US are expected to achieve lower efficiency gains in this respect, although in Japan and Europe, from very low initial energy intensity in Japan and Europe.

Figure 7 - Observed energy price and EIA scenarios 1980-2035 (constant 2005 USD)

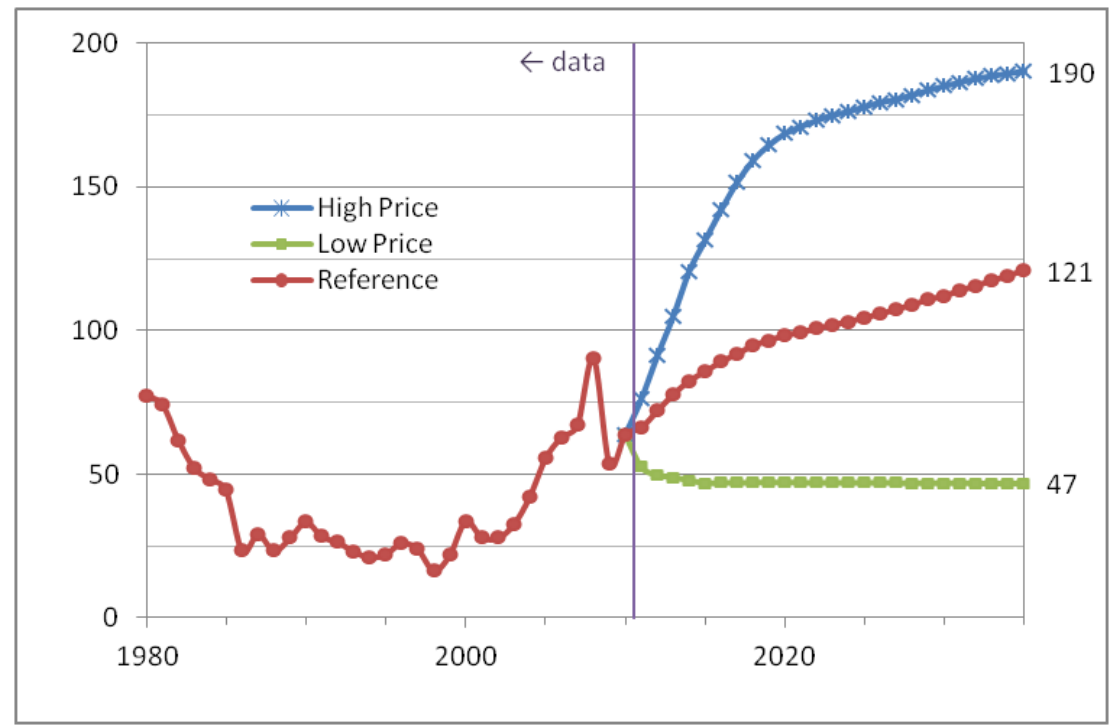

Source: EIA.

Energy use is determined by the energy price and induced adjustment of economies towards less intensive technologies in the case of high energy prices. Beyond this 'economic' adjustment, we need to consider an autonomous strand of technical progress in the energy domain. Major technological breakthrough or societal changes may occur in the next two decades, leading to a dramatic increase in the energy efficiency of our economies. Such changes are not embedded in existing data and therefore are not included in our econometric estimations. They can be introduced in the projections as exogenous shocks.

Results for energy intensity are shown in Table 15 along with the impacts of energy price scenarios. As in the previous case, columns 4 and 5 of Table 15 show the results of our assumptions about the energy price on energy use efficiency, measured in boe per US\$1,000 of GDP. Although in this case, the impact on countries differs, the world average order of magnitude is the same as for the scenarios for energy price.

Regarding technological progress, for the low scenario we assume a 50\% increase (compared to our reference scenario) in energy efficiency for the high income countries at the 2050 horizon, but no change for the other countries. In the high scenario, we assume a $50 \%$ increase in energy efficiency for low and middle income countries at the 2050 horizon, but no change for the other countries. 
Table 15 - Energy intensity, 2035 (barrel per \$1,000 of GDP)

\begin{tabular}{|c|c|c|c|c|c|}
\hline & \multirow[b]{2}{*}{ Ref } & \multicolumn{2}{|c|}{ Impact of energy price } & \multicolumn{2}{|c|}{ Impact of techno. progr. } \\
\hline & & low & high & low & high \\
\hline United States of America & 0.92 & -0.06 & +0.13 & -0.18 & +0.00 \\
\hline Japan & 0.65 & -0.04 & +0.09 & -0.12 & +0.00 \\
\hline European Union & 0.72 & -0.05 & +0.10 & -0.12 & -0.01 \\
\hline Brazil & 1.30 & -0.09 & +0.20 & +0.00 & -0.25 \\
\hline Russian Federation & 2.83 & -0.32 & +0.59 & +0.00 & -0.54 \\
\hline India & 2.28 & -0.14 & +0.32 & +0.00 & -0.44 \\
\hline China & 2.21 & -0.13 & +0.31 & +0.00 & -0.42 \\
\hline Latin America & 1.22 & -0.11 & +0.21 & -0.00 & -0.23 \\
\hline Middle east and North Africa & 1.43 & -0.19 & +0.35 & -0.08 & -0.19 \\
\hline Sub-Saharan Africa & 2.51 & -0.23 & +0.44 & +0.00 & -0.48 \\
\hline Rest of Asia & 1.76 & -0.12 & +0.26 & -0.10 & -0.23 \\
\hline Rest of the World & 1.03 & -0.08 & +0.17 & -0.15 & -0.04 \\
\hline Total world & 1.36 & -0.11 & +0.22 & -0.09 & -0.17 \\
\hline
\end{tabular}

Source: MaGE, authors' calculation.

\subsection{Total factor productivity}

Technological progress in the various regions of the world is an important mechanism, which varies according to the scenario. These changes can be driven by national autonomous technological developments or international transfers of technology. In the low scenario we consider a 50\% drop in TFP growth rates for low- and middle-income countries compared to our baseline scenario, and a $25 \%$ drop for high-income countries. In the high scenario, we assume a 50\% increase in TFP growth rates for low- and middle-income countries, and a $25 \%$ increase in TFP growth rates for high-income countries.

Table 16 - Average annual TFP growth rate, 2012-2035

\begin{tabular}{lrrr}
\hline & Ref & low & high \\
\hline United States of America & 0.98 & -0.25 & +0.25 \\
Japan & 1.71 & -0.34 & +0.30 \\
European Union & 1.33 & -0.29 & +0.30 \\
Brazil & 1.65 & -0.77 & +0.68 \\
Russian Federation & 3.91 & -1.80 & +1.54 \\
India & 3.26 & -1.50 & +1.28 \\
China & 4.19 & -1.89 & +1.56 \\
Latin America & 1.76 & -0.83 & +0.75 \\
Middle east and North Africa & 1.54 & -0.60 & +0.67 \\
Sub-Saharan Africa & 2.28 & -0.95 & +0.85 \\
Rest of Asia & 2.32 & -0.37 & +0.37 \\
Rest of the World & 1.66 & -0.22 & +0.26 \\
\hline Total world & 1.58 & -0.13 & +0.25 \\
\hline
\end{tabular}

Source: MaGE, authors' calculation. 


\subsection{International capital mobility}

The last factor of production is capital. Capital is depreciating at a constant rate in our growth model, consistent with the specification used in MIRAGE. In considering gross investment, we need to take account of two drivers. First, saving is driven by demography (as already discussed) and per capita income. Second, the difference between domestic saving and domestic investment is driven by the international mobility of capital to which we apply a shock. We have two opposite cases: in the low case, countries are returning to capital autarky, in the high case, they converge to the highest level of capital mobility observed (with no direct gains for low- and middle-income countries). Low mobility has a positive impact for current account surplus countries (India, Russia or China).

Under the high mobility assumption, we reduce the Feldstein-Horioka correlation coefficient of the OECD countries: the correlation between domestic saving and domestic investment is lower for the OECD country group and takes the value estimated for non-OECD countries which remains unchanged. The total amount of saving (which equals world investment) remains almost unaffected by this change, whereas the allocation of investment among countries is modified. Since the correlation is smaller for the OECD countries, investment in these countries diminishes for a given amount of saving. In turn, investment is increasing in the non-OECD countries where it is associated with lower TFP. At the world level, this induces a negligible decrease in overall GDP, while developed countries suffer a $-0.2 \%$ loss in GDP compensated for by a gain of a similar magnitude in the developing countries (Table 17).

Table 17 - Average investment rate, 2012-2035 (percentage of GDP)

\begin{tabular}{lrrr}
\hline & Ref & low & high \\
\hline United States of America & 15.3 & -0.73 & -2.36 \\
Japan & 20.7 & -0.15 & -3.02 \\
European Union & 17.4 & -0.07 & -2.54 \\
Brazil & 17.6 & -1.71 & +2.33 \\
Russian Federation & 21.2 & +3.70 & +6.32 \\
India & 20.7 & +1.08 & +4.39 \\
China & 32.2 & +0.35 & +6.78 \\
Latin America & 18.8 & -0.36 & +0.39 \\
Middle east and North Africa & 21.0 & +2.05 & +3.71 \\
Sub-Saharan Africa & 16.6 & -0.36 & +2.73 \\
Rest of Asia & 23.4 & +0.56 & +1.55 \\
Rest of the World & 19.9 & +0.82 & -2.01 \\
\hline Total world & 18.8 & +0.20 & -0.66 \\
\hline
\end{tabular}

Source: MaGE, authors' calculation.

\subsection{Combining the different assumptions of the two scenarios in MaGE}

We now implement jointly all the assumptions in the two scenarios simulated with MaGE. Table 18 shows the results for GDP growth which take account of all the relations and feed-backs among the variables in the MaGE model.

In the first panel in Table 18, column (1) presents annual growth rates for the regions included in MIRAGE and columns (2) and (3) show the difference between each scenario and the reference case. China shows a $6 \%$ average growth rate to 2035 . This is the highest figure among regions considered. 
The high scenario corresponds to 2.7 percentage points additional growth and symmetrically -2.7 percentage points corresponds to the low scenario. This symmetry is not observed systematically, but depends on regional composition. We observe contrasts for the two scenarios for developing economies, with a range of 3.7 percentage points growth between the two scenarios, but much less so for the developed economies (resp. 0.6 percentage points). In the second panel, column (4) shows GDP levels at 2005 US\$ exchange rates and prices. Columns (5) and (6) indicate the percentage deviations from the 2035 level. We observe that the scenarios combining different assumptions show stark contrasts. World GDP is $33 \%$ higher (15\% lower) in the high (low) scenario, compared to the reference case.

Table 18 - GDP projections under the high and low scenarios

\begin{tabular}{|c|c|c|c|c|c|c|c|c|c|}
\hline & \multicolumn{3}{|c|}{ GDP growth } & \multicolumn{3}{|c|}{ GDP in 2035} & \multicolumn{3}{|c|}{ Share of world GDP } \\
\hline & $(1)$ & (2) & (3) & (4) & (5) & (6) & $(7)$ & $(8)$ & (9) \\
\hline & Ref & low & high & Ref & low & high & Ref & low & high \\
\hline United States of America & 1.74 & -0.12 & +0.44 & 20562 & -2.75 & +10.49 & 20.3 & +2.99 & -3.40 \\
\hline Japan & 1.53 & -0.12 & +0.20 & 6749 & -2.63 & +4.53 & 6.7 & +0.99 & -1.42 \\
\hline European Union & 1.43 & -0.02 & +0.80 & 20458 & -0.37 & +19.81 & 20.2 & +3.55 & -1.97 \\
\hline Brazil & 2.97 & -1.01 & +1.31 & 2299 & -20.31 & +33.78 & 2.3 & -0.14 & +0.02 \\
\hline Russian Federation & 4.13 & -1.51 & +2.34 & 2481 & -28.55 & +66.66 & 2.5 & -0.38 & +0.63 \\
\hline India & 5.96 & -2.33 & +2.48 & 5450 & -40.10 & +70.23 & 5.4 & -1.58 & +1.52 \\
\hline China & 6.07 & -2.70 & +2.76 & 17217 & -44.79 & +80.48 & 17.0 & -5.93 & +6.12 \\
\hline Latin America & 3.34 & -0.79 & +0.76 & 4674 & -16.22 & +18.38 & 4.6 & -0.05 & -0.50 \\
\hline Middle east and North Africa & 3.47 & -0.57 & +0.79 & 5440 & -11.86 & +19.05 & 5.4 & +0.21 & -0.55 \\
\hline Sub-Saharan Africa & 5.09 & -1.43 & +1.68 & 2727 & -27.04 & +43.99 & 2.7 & -0.37 & +0.23 \\
\hline Rest of Asia & 3.98 & -0.91 & +1.37 & 7154 & -18.24 & +35.05 & 7.1 & -0.25 & +0.12 \\
\hline Rest of the World & 2.69 & -0.07 & +0.63 & 6039 & -1.61 & +14.99 & 6.0 & +0.96 & -0.80 \\
\hline Total world & 2.84 & -0.74 & +1.27 & 101251 & -15.24 & +32.73 & 100.0 & & \\
\hline Total Developed & 1.64 & -0.04 & +0.52 & 52842 & -0.95 & +12.57 & 52.2 & +8.80 & -7.93 \\
\hline Total Developing & 4.72 & -1.67 & +2.01 & 48409 & -30.84 & +54.73 & 47.8 & -8.80 & +7.93 \\
\hline
\end{tabular}

Note: Column (4) is in 2005 US\$ billions. Columns (1), (5) , (6) and (7) are percentages and columns (2), (3), (8), (9) are percentage points.

Source: MaGE, authors calculations.

GDP trajectories are plotted in Figure 8 and also show large contrasts. This is the result of opening a Pandora's box of growth projections. The continuous line corresponds to the 'High Ref' scenario for each country. Table 18 shows that China will achieve US\$ 17,217 GDP in 2035 in the reference scenario, and $80.5 \%$ more in the high scenario, that is, US\$31,073 GDP in 2035, shown on the upper dotted curve in Figure 8. The interpretation is symmetric ('Low Ref' scenario) for each country and each low dotted curve. Figure 8 confirms that the range of outcomes for GDP is very large for developing countries, compared to the developed ones. The highest in the range is China which overtakes the US in 2030 in the high scenario. Similarly, India overtakes Japan at the same horizon in the high scenario. Our objective in this section is to discuss the implications for world trade patterns of such extreme assumptions. 
Figure 8 - GDP in the 'High Ref' and 'Low Ref' scenarios, 2000-2035 (2005 US\$ billion)

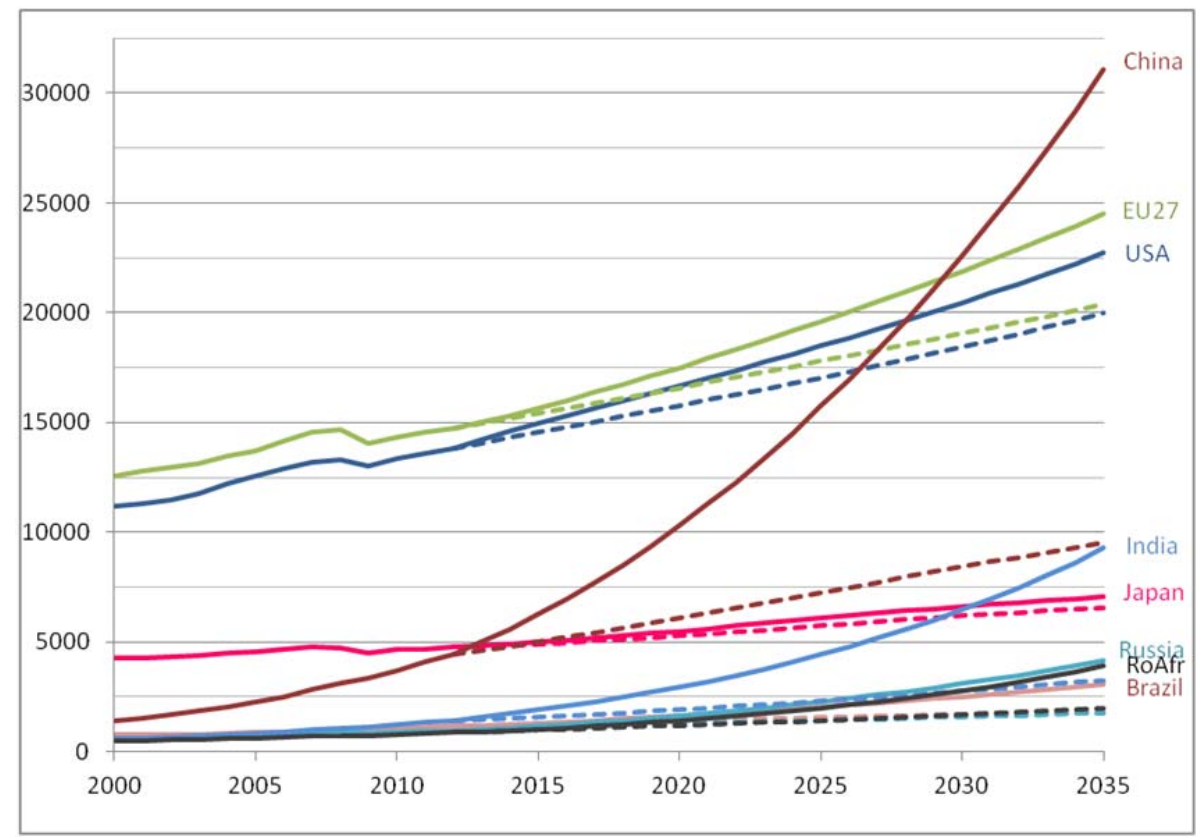

Note: continuous line is 'High Ref'; dotted line is 'Low Ref'.

Source: MaGE, authors' calculation.

Due to the intrinsic link between all the factors that receive shocks in our scenarios, it is not possible to determine precisely the relative impact of each shock. However, we can observe the impact of individual variables on GDP in 2035. Results are shown in Figure 9.

The individual shocks (colored bars in Figure 9) allow us to infer that TFP is the main contributor to GDP changes in our differentiated scenarios, along with capital mobility, energy price, female labor participation and migration. For example, in the USA and the European Union, migrant inflows account for around the same amount of extra GDP as TFP gains in the high scenario. Although they are considered one at a time, demography, education and energy productivity seem to have marginal impacts; their sum is not negligible and act more as catalysts: education fuels TFP; energy productivity inflates the benefits of a low energy price; and demography drives saving.

If we compare this outcome with the outcome if all the variables suffer shocks simultaneously (black crosses in Figure 9), orders of magnitude are maintained compared to the sum of individual variable shocks, for all developing countries. This pattern is not observed for the three main developed country blocks (USA, EU and Japan), due mainly to the following two effects: world equilibrium of saving and investment, and the conjunction of TFP and education scenarios. For instance, in the 'High Ref' scenario, developing countries increase their share of world investment, leading to capital shortage in Japan, whose growth depends heavily on capital accumulation. 
Figure 9 - Contributions from scenarios on individual variables to GDP level, 2035.

a. Low ref

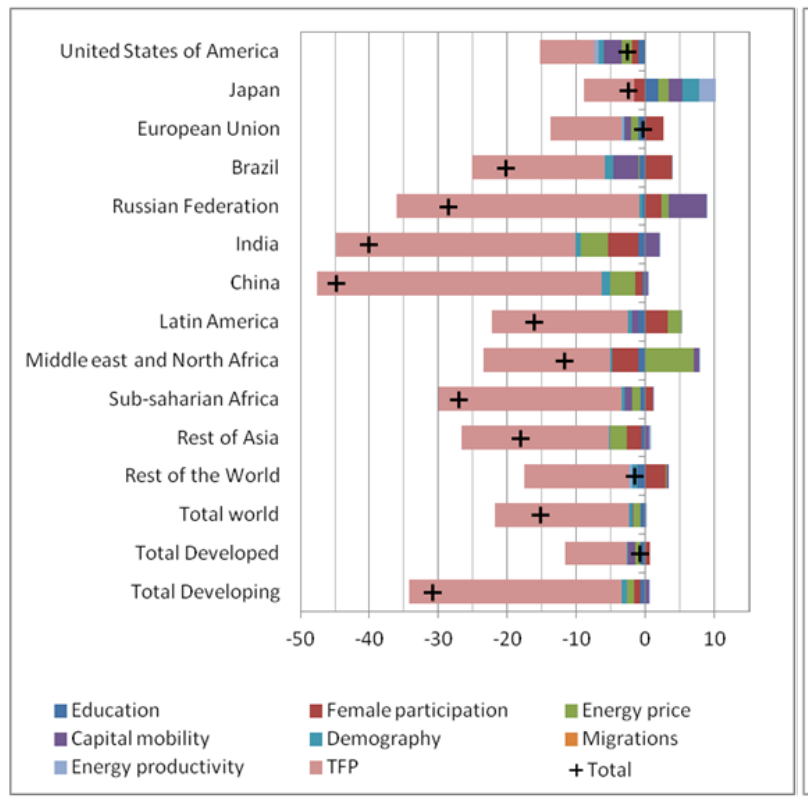

b. High ref

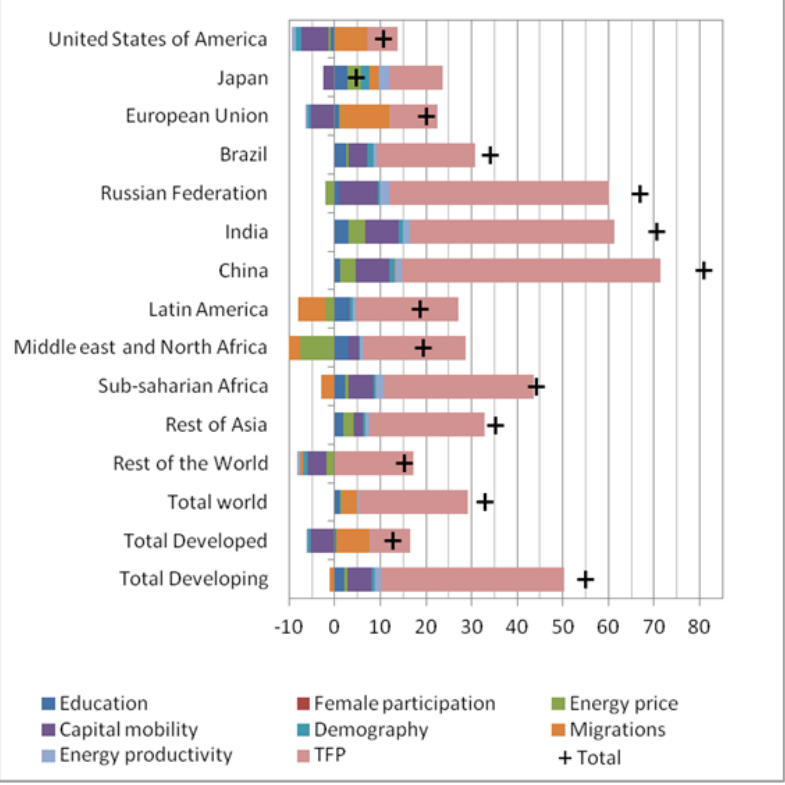

Source: MaGE, authors' calculation. 


\section{CONTRASTING WORLD TRADE PATTERNS AT THE 2035 HORIZON}

We next present the results of the two scenarios ('Low sim' and 'High sim') simulated in MIRAGE.

\subsection{World trade patterns}

World trade patterns are fundamentally shaped by gravity-like determinants. We expect the volume of world exports to be determined by changes in GDP, comparative advantage, and trade costs. We now add the shocks on transaction costs and tariffs for goods and NTM in services, as described in Table 6, to obtain the 'Low sim' and 'High sim' scenarios. The overall result is depicted in Figure 10. Under the 'High Sim' scenario, developing economies will have buoyant exports of goods, growing at $8.4 \%$ annually ( $7.4 \%$ in the 'High Ref' scenario with no further trade liberalization). This figure is even larger for services. This contrasts with the 'Low Sim' scenario where GDP grows much slower, especially for the developing countries, and where trade costs (tariffs and transaction costs) are increasing. The low scenarios are particularly penalizing for goods, especially the 'Low Sim': goods have to be transported and are subject to tariff wars, while services are only subject to regulations, which are assumed to be constant in the low scenario. Finally, developing countries' exports are strongly affected by the combination of transaction costs, tariff and growth assumptions in the low scenario.

\section{Figure 10 - GDP (volume) and exports (volume, incl. intra) growth rates in Low-vs-High Ref and Sim scenarios, 2012-2035}

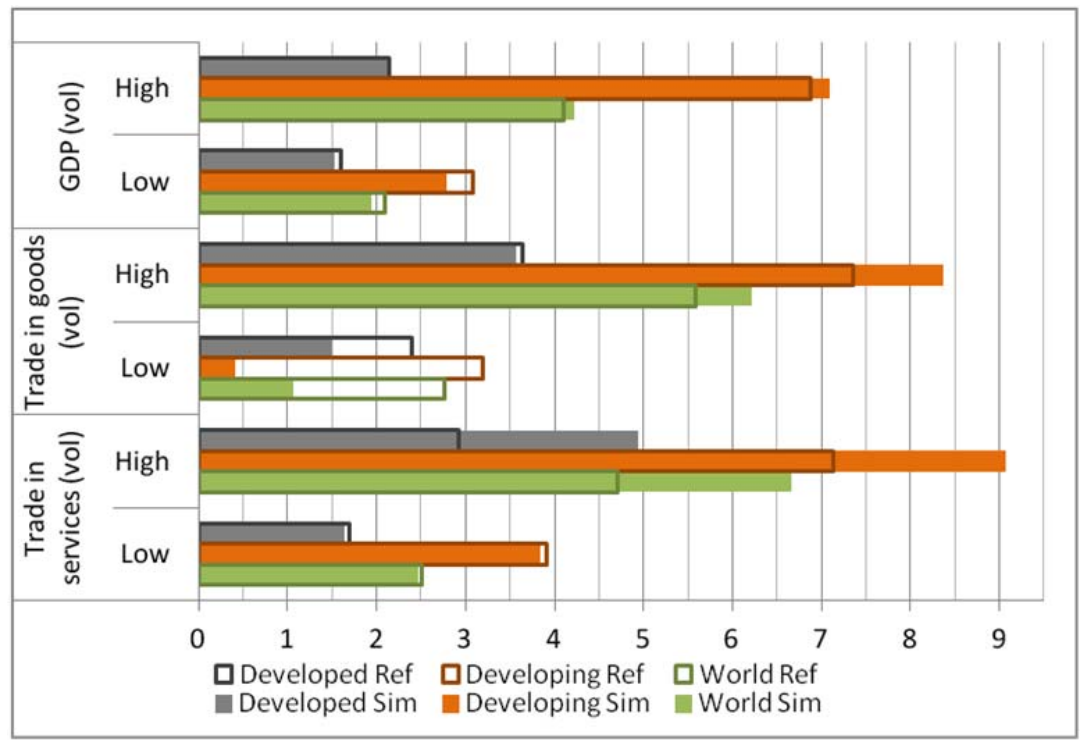

Note: average annual growth rates (percentages). Developing countries' trade in services grows annually by 7\% in the 'High Ref' scenario, compared to $9 \%$ in the 'High Sim' scenario.

Source: MIRAGE, authors' calculation.

The annual growth rates for GDP and exports of goods and services shown in Figure 10, suggest that trade to income elasticity will differ across the two scenarios and the two regions of the world economy. Table 19 presents the computed trade elasticity. In the 'High Sim' scenario elasticity is 1.5 at the world level. This is low compared to historical levels, and particularly compared to the 1990s, the decade when many global value chains were established: elasticity in the 1990s was 2.8. In our projection, we return to the values observed in the 1960s. Under all circumstances, elasticity is higher for the developed economies which will increase trade with a faster growing developing world. Under 
the 'Low Sim' scenario, we have (slow) growth and no trade in the developing world (elasticity 0.4), while trade and income follow the path of the developed economies.

Although our trade scenarios have only a marginal effect on GDP compared to the determinants of growth in MaGE, they tend to reshape trade patterns profoundly over the next 20 years. For instance, for goods, a trade war would imply an almost three-fold reduction in growth in trade of goods at world level, compared to an $11 \%$ increase in growth in the case of further liberalization.

Table 19 - Trade to income elasticity (goods), 2012-2035

\begin{tabular}{lrr}
\hline & High Sim & Low Sim \\
\hline Developed & 1.78 & 1.00 \\
Developing & 1.19 & 0.38 \\
World & 1.49 & 0.69 \\
\hline
\end{tabular}

Note: elasticity computed on the exports.

Source: MIRAGE, author's calculation

\subsection{Intra-regional trade}

Trade patterns are also affected by the share of intra-regional trade in world trade. As a result of the gravity forces shaping world trade, we expect South-South trade to grow faster. However, growth in South-South trade may not necessarily be driven by the presence of FTAs because the current levels of market integration currently agreed for the South are too low to have a significant impact. This contrasts with integrated regions such as the EU and, to a lesser extent, NAFTA. Thus, in the 'Low Sim' scenario, we observe that the EU and NAFTA manage to maintain their initial share of world trade at the 2035 horizon, notwithstanding a 35\% increase in the volume of world exports. The fact that tariffs within FTAs are supposed not to be subject to tariff wars in the 'Low Sim' scenario also contributes to this result.

In contrast, in the high scenario, most trade growth occurs in the developing economies, shifting the center of gravity of international trade to the South. World trade will quadruple in volume, EU exports will increase by $55 \%$, and the EU's share dramatically decreases. A similar pattern is observed for NAFTA (with a 52\% increase in exports). FTAs in the South do not deliver since the shares of ASEAN and Mercosur are kept constant in all scenarios. This reduction in the share of regional trade in world trade in the high scenario, could be reversed were ambitious and new FTAs (e.g. those under negotiation for the Pacific and to a lesser extent the Transatlantic levels) to be signed. We do not model such outcomes.

\subsection{Regional specialization}

Alternative growth paths for the world economy will be conducive to different country export specialization. In the 'High Sim' and 'Low Sim' scenarios considered here, accumulation of human as well as physical capital will be different. This will shape countries' comparative advantages. A good illustration of this mechanism is provided by China's specialization, shown in Figure 11. The 'High Sim' scenario will further increase China's specialization in the electronic sector as opposed to textiles. In the 'Low Sim' scenario, with less physical and human capital per worker, China will maintain its specialization in textiles and increase specialization in other manufacturing, while progressively losing ground in electronics. These results suggest that countries' specialization is not

\footnotetext{
${ }^{11}$ More details on the future of regional trade are provided in our companion paper (Fontagné L., Fouré J. and A. Keck, 2013).
} 
completely pre-determined if one considers seriously the wide range of possible outcomes for medium term growth.

Figure 11 - Share of sectors in China total export (volume)
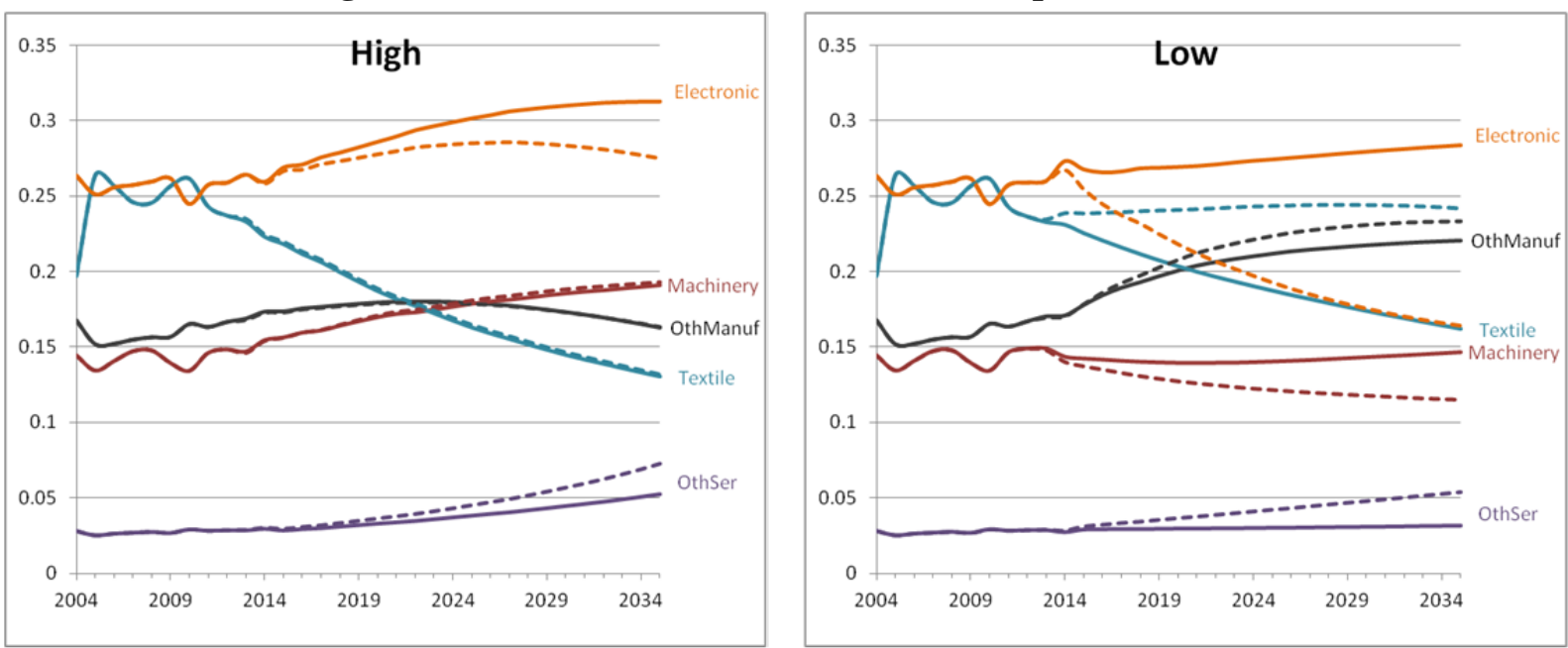

Notes: Solid lines correspond to 'High Ref' (left) and 'Low Ref' (right) scenarios; dotted lines correspond respectively to 'High Sim' and 'Low Sim'.

Source: MIRAGE, authors' calculation.

Figure 11 shows the patterns for the different baselines. The difference between the 'High Ref' and 'High Sim' scenarios for China remains small, showing only a slight shift towards services exports away from electronics. In the low scenarios, almost all the shift in Chinese exports to textiles away from electronics is due to shocks to trade costs. These patterns occurs because these sectors represent China's most important exports, and because reverting to post-Tokyo Round tariffs would lead to a multiplication of tariffs on electronics of between 1.1 and 123 (for Canada), and a factor of 10 for the USA and 20 for Australia and New Zealand. In contrast, for the textile sectors it is lower than 5.3. This supports the claim that, except for the huge sectoral differentiation provided by trade policy shocks, the main determinants of national specialization in a CGE are baseline assumptions.

These widely contrasting scenarios for country specialization have a profound impact on the shape of world production in several sectors. Figure 12 depicts the effects for the automotive sector. We observe that Chinese production of cars rapidly overtakes European production in the high scenario, but not in the low scenario. This pattern applies also to comparison between China and the US in this sector. In all the scenarios, the Japanese car industry is overtaken by China. Again, with the exception of electronics (see Figure 13) and textiles, in the trade war scenario, countries' market shares are determined mainly by the baseline, rather than the trade policies we implemented. 
Figure 12 - Regional shares in world car and truck production (volume)
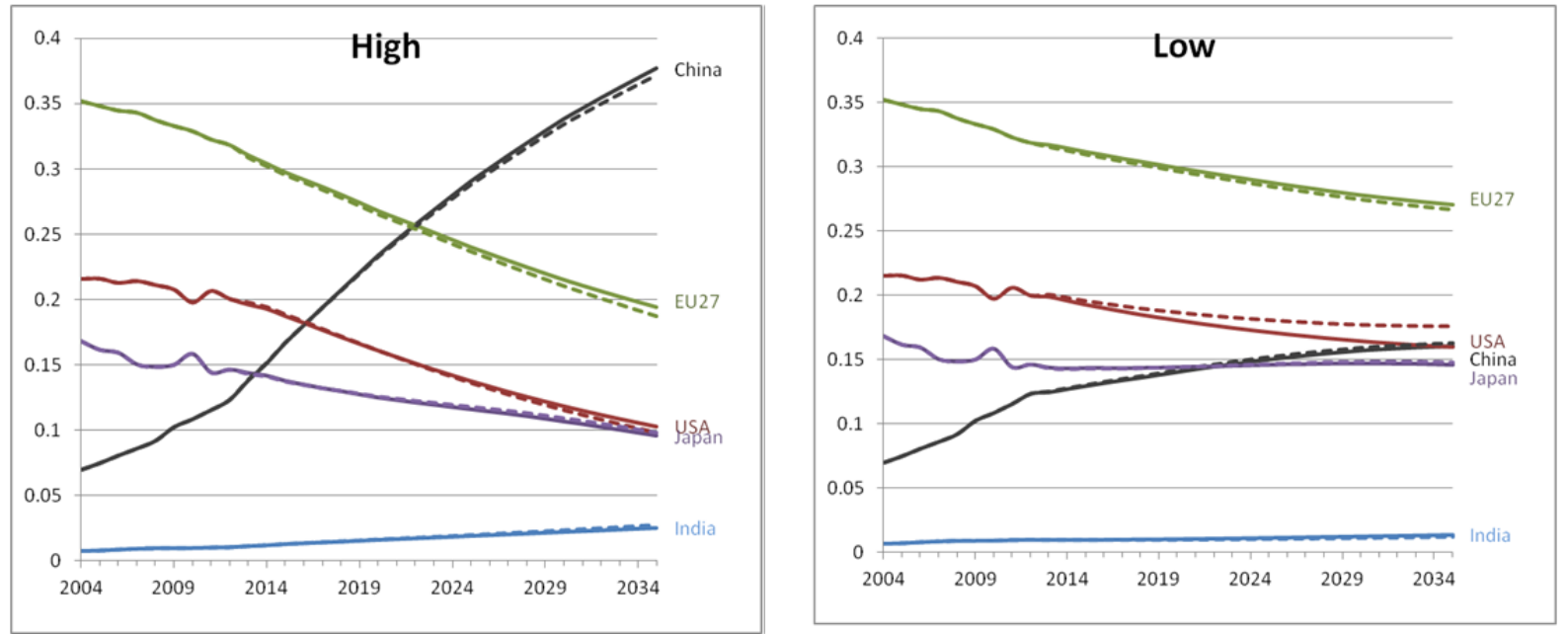

Notes: Solid lines correspond to 'High Ref' (left) and 'Low Ref' (right) scenarios; dotted lines correspond respectively to 'High Sim' and 'Low Sim'.

Source: MIRAGE, authors' calculation.

Figure 13 - Regional shares in world Electronic Devices production (volume)
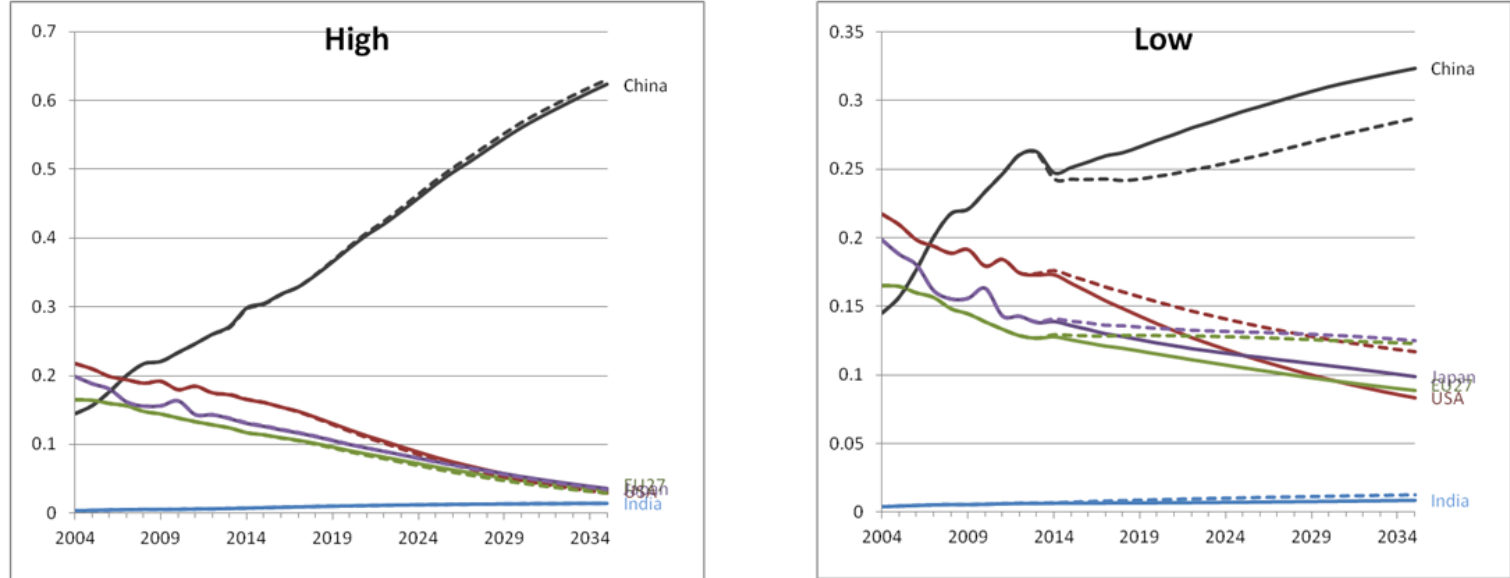

Notes: Continuous lines correspond to 'High Ref' (left) and 'Low Ref' (right) scenarios; dotted lines correspond respectively to 'High Sim and 'Low Sim'.

Source: MIRAGE, authors' calculation. 


\section{CONCLUSION}

This paper has developed a comprehensive methodological framework for projecting 'open-minded' world trade patterns at a medium and long-run horizon, based on scenarios for the world economy. We investigated the determinants of past economic growth and international trade developments in order to build sound baseline assumptions. We implemented contrasting scenarios encompassing a wide range of potentialities. The combination of MaGE, a growth model, with MIRAGE a dynamic multisectoral CGE model of the world economy proved fruitful. Our results point to the need for careful building of baseline scenarios when evaluating policies in dynamic general equilibrium, given that the magnitude of the changes in world trade patterns when baselines differ is at least as large as when trade policy shocks are imposed. Due to the huge uncertainty surrounding future paths for the global economy, our work highlights the important role of key assumptions in their modeling. These results call for transparency, replicability and inter-operability of modeling frameworks. In order to make general equilibrium inference as reliable and transparent as possible we plead for the Pandora's box of growth and trade patterns projections to be unlocked. 


\section{REFERENCES}

Aghion, P. \& Howitt, P. (1992), 'A Model of Growth Through Creative Destruction', Econometrica 60(2), 323-351.

Anderson, K. \& Strutt, A. (2012), 'The changing geography of world trade: Projections to 2030', Journal of Asian Economics 23(4), 303--323.

Armington, P. S. (1969), 'A Theory of Demand for Products Distinguished by Place of Production', International Monetary Fund Staff Papers 16(1), 159-178.

Asian Development Bank (2011), 'Asia 2050: realizing the Asian century', Emerging Markets Forum, Asian Development Bank, Manilla.

Barro, R. J. \& Lee, J.-W. (2013), 'A new data set of educational attainment in the world, 1950-2010', Journal of Development Economics (forthcoming).

Böhringer, C.; Löschel, A. \& Rutherford, T. (2009), Policy Analysis Based on Computable Equilibrium (PACE), in V. Bosetti; R. Gerlagh \& S. P. Schleicher, ed., 'Modelling sustainable development: transitions to a sustainable future', Edward Elgar Publishing, Northampton, pp. 202-219.

Bouët, A.; Bureau, J.-C.; Decreux, Y. \& Jean, S. (2005), 'Multilateral Agricultural Trade Liberalisation: The Contrasting Fortunes of Developing Countries in the Doha Round', The World Economy 28(9), 1329-1354.

Bouët, A.; Mevel, S. \& Orden, D. (2007), 'More or Less Ambition in the Doha Round: Winners and Losers from Trade Liberalisation with a Development Perspective', The World Economy 30(8), 12531280.

British Petroleum (2010), 'BP statistical review of world energy', British Petroleum, London.

Burniaux, J. \& Truong, T. (2002), 'GTAP-E: An Energy-Environmental Version of the GTAP Model', GTAP Technical Paper No. 16.

Chappuis, T. \& Walmsley, T. (2011), 'Projections for World CGE Model Baselines', GTAP Research Memoranda No. 22.

Chateau, J.; Dellink, R.; Lanzi, E. \& Magné, B. (2012), 'Long-term economic growth and environmental pressure: reference scenarios for future global projections', draft presented at the 2012 GTAP conference, Gevena.

Coelli, T. J. \& Rao, D. S. (2005), 'Total factor productivity growth in agriculture: a Malmquist index analysis of 93 countries, 1980-2000', Agricultural Economics 32(s1), 115-134.

Deardorff, A. V. \& Stern, R. M. (1983), 'Economic effects of the Tokyo Round', Southern Economic Journal 49, 605-624.

Decreux, Y. \& Valin, H. (2007), 'MIRAGE, Updated Version of the Model for Trade Policy Analysis Focus on Agriculture and Dynamics', CEPII Working Paper No. 2007-15.

Duval, R. \& de la Maisonneuve, C. (2010), 'Long-run growth scenarios for the world economy', Journal of Policy Modeling 32(1), 64-80. 
European Commission (2012), 'Global Europe 2050', Directorate-General for Research and Innovation, Socio-economic Sciences and Humanities, Brussels.

Feldstein, M. \& Horioka, C. (1980), 'Domestic Saving and International Capital Flows', Economic Journal 90(358), 314-29.

Fontagné, L.; Fouré, J. \& Ramos, M. P. (2013), 'General Equilibrium Long-term path of the Word Economy', CEPII Working Paper (forthcoming).

Fontagné, L.; Guillin, A. \& Mitaritonna, C. (2011), 'Estimations of tariff equivalents for the services sectors', CEPII Working Paper No. 2011-24.

Fontagné, L.; Fouré, J. \& Keck, A. (2013), 'Simulating world trade in the decades ahead: Driving forces and policy implications', WTO Working Paper (forthcoming).

Fouré, J.; Bénassy-Quéré, A. \& Fontagné, L. (2012), 'The Great Shift: Macroeconomic projections for the world economy at the 2050 horizon', CEPII Working Paper No. 2012-03.

Fouré, J.; Bénassy-Quéré, A. \& Fontagné, L. (2010), 'The world economy in 2050: a tentative picture', CEPII Working Paper No. 2010-27.

Freund, C. (2009), 'The trade response to global downturns', World Bank Policy Research Working paper No. 5015.

Hertel, T.; Hummels, D.; Ivanic, M. \& Keeney, R. (2007), 'How confident can we be of CGE-based assessments of Free Trade Agreements?', Economic Modelling 24(4), 611-635.

Hummels, D. \& Schaur, G. (2012), 'Time as a trade barrier', NBER Working Paper No. 17758.

Ianchovichina, E. \& McDougall, R. (2000), Theoretical Structure of Dynamic GTAP, in E. Ianchovichina \& T. L. Walmsley, ed., 'Dynamic Modeling and Applications for Global Economic Analysis', Center for Global Trade Analysis, Department of Agricultural Economics, Purdue University, West Lafayette.

IEA (2011), World Energy Outlook 2011, International Energy Agency, Paris.

International Monetary Fund (2012), 'Changing patterns of global trade', International Monetary Fund, Washington, D.C.

Johansson, Ås.; Guillemette, Y.; Martin, F.; Turner, D.; Nicoletti, G.; de la Maisonneuve, C.; Bagnoli, P.; Bousquet, G. \& Spinelli, F. (2013), 'Long-Term Growth Scenarios', OECD Economics Department Working Papers (1000).

Laborde, D. \& Valin, H. (2011), 'Assessing the EU biofuel land use change effects: estimates with the MIRAGE-BioF model and sensitivity analysis', mimeo, IFPRI.

Ludena, C.; Hertel, T.; Preckel, P.; Foster, K. \& Nin, A. (2007), 'Productivity growth and convergence in crop, ruminant, and nonruminant production: measurement and forecasts', Agricultural Economics 37(1), 1-17.

Masson, P. R.; Bayoumi, T. A. \& Samiei, H. (1998), 'International Evidence on the Determinants of Private Saving', World Bank Economic Review 12(3), 483-501. 
van der Mensbrugghe, D. (2005), 'LINKAGE Technical Reference Document: Version 6.0', World Bank, Washington, D.C..

Minor, P. \& Tsigas, M. (2008), 'Impacts of Better Trade Facilitation in Developing Countries"11th Annual Conference on Global Economic Analysis, Helsinki.

Nin, A.; Hertel, T. W.; Foster, K. A. \& Rae, A. N. (2001), 'Productivity Growth And Catching-Up: Implications For China's Trade In Livestock Products'(20590), Technical report, American Agricultural Economics Association (New Name 2008: Agricultural and Applied Economics Association).

Paltsev, S.; Reilly, J. M.; Jacoby, H. D.; Eckaus, R. S.; McFarland, J.; Sarofim, M.; Asadoorian, M. \& Babiker, M. (2005), 'The MIT Emissions Prediction and Policy Analysis (EPPA) Model: Version 4', Technical report, MIT.

Petri, P. \& Zhai, F. (2013), 'Navigating a Changing World Economy: ASEAN, the People's Republic of China, and India', ADBI Working Paper No. 404.

Ward, K. (2011), The world in 2050: Quantifying the shift in the global economy, HSBC London.

Wilson, D. \& Purushothaman, R. (2003), 'Dreaming With BRICs: The Path to 2050', Goldman Sachs Global Economics Paper No. 99.

Wolff, E. N. (1999), 'The productivity paradox: evidence from indirect indicators of service sector productivity growth', The Canadian Journal of Economics 32(2), 281-308.

World Bank (2007), 'Global economic prospects: Managing the next wave of globalization', The World Bank, Washington, D.C. 


\section{APPENDIX}

\section{APPENDIX A: TRADE WAR DATA}

Table A1 - Post-Tokyo round tariffs by sector

Table II. Post-Kennedy Round Base Rate Tariffs on Industrial Products by Sector in the Major Industrialized Countries (Percent; Weighted by Own-Country

\begin{tabular}{|c|c|c|c|c|c|c|c|c|c|c|c|c|c|c|c|c|c|c|c|}
\hline & $\mathrm{ALA}^{*}$ & ATA & BLX & $\mathrm{CND}^{+}$ & DEN & FIN & FR & GFR & IRE & IT & $\mathrm{JPN}^{+}$ & NL & $\mathrm{NZ}$ & NOR & SWD & swz & UK & US & ALL \\
\hline Textiles & 21.5 & 18.7 & 9.5 & 18.9 & 12.1 & 24.1 & 9.8 & 10.3 & 10.7 & 7.5 & 3.3 & 11.8 & 14.2 & 16.2 & 10.9 & 8.2 & 9.2 & 14.4 & 10.7 \\
\hline Wearing Apparel & 61.8 & 36.3 & 16.7 & 25.4 & 16.4 & 37.2 & 16.7 & 16.8 & 16.4 & 16.6 & 13.8 & 16.8 & 58.7 & 22.8 & 14.4 & 15.5 & 16.9 & 27.8 & 20.7 \\
\hline Leather Prod & 25.7 & 9.1 & 4.1 & 8.2 & 3.6 & 12.6 & 3.3 & 5.1 & 5.4 & 1.7 & 3.0 & 5.2 & 15.3 & 6.6 & 4.8 & 2.8 & 2.8 & 5.6 & 4.5 \\
\hline Wood Products & 13.6 & 4.8 & 3.2 & 5.8 & 4.4 & 0.5 & 3.3 & 3.9 & 3.2 & 1.0 & 0.3 & 3.6 & 11.7 & 2.0 & 0.9 & 5.0 & 4.0 & 3.6 & 2.7 \\
\hline Paper, Pap Prod & 7.1 & 15.9 & 9.3 & 11.8 & 10.8 & 8.0 & 7.6 & 7.1 & 10.9 & 3.7 & 2.1 & 8.4 & 20.9 & 2.9 & 3.0 & 6.6 & 6.6 & 0.5 & 5.8 \\
\hline Print \& Publ & 1.8 & 2.4 & 2.4 & 5.7 & 4.4 & 1.8 & 3.4 & 3.3 & 2.4 & 2.7 & 0.2 & 3.5 & 1.1 & 4.3 & 0.2 & 0.9 & 3.3 & 1.1 & 2.9 \\
\hline Chemicals & 5.8 & 8.1 & 11.6 & 7.9 & 11.9 & 3.1 & 10.9 & 11.6 & 10.7 & 11.8 & 6.2 & 11.9 & 10.0 & 8.1 & 6.3 & 1.1 & 11.4 & 3.8 & 9.4 \\
\hline Rubber Products & 13.8 & 14.6 & 6.2 & 12.2 & 6.7 & 13.9 & 5.2 & 5.7 & 5.6 & 4.0 & 1.5 & 6.1 & 9.5 & 7.3 & 6.5 & 2.0 & 4.0 & 3.6 & 5.8 \\
\hline Nonmet Min Prod & 11.6 & 8.9 & 5.2 & 9.5 & 6.7 & 3.8 & 7.0 & 5.4 & 6.0 & 3.3 & 0.6 & 4.4 & 13.8 & 2.8 & 3.1 & 3.5 & 3.2 & 9.1 & 5.8 \\
\hline Glass, GI Prod & 15.2 & 17.5 & 9.9 & 11.3 & 9.7 & 25.4 & 9.8 & 10.2 & 9.5 & 9.6 & 7.5 & 9.3 & 15.4 & 10.5 & 9.3 & 4.5 & 10.4 & 10.7 & 10.5 \\
\hline Nonfer Metal & 5.3 & 4.5 & 1.9 & 2.0 & 8.1 & 1.2 & 3.1 & 2.3 & 8. & 2.2 & 1.1 & 4.3 & 9.3 & 1.1 & 0.9 & 4.3 & 2.0 & 1.2 & 2.0 \\
\hline Metal Products & 24.1 & 19.3 & 7.7 & 14.1 & 7.9 & 9.6 & 7.8 & 8.0 & 7.7 & 8.0 & 6.9 & 7.8 & 29.7 & 6.3 & 5.3 & 3.8 & 8.0 & 7.5 & 9.0 \\
\hline Nonelec Mach & 14.2 & 10.8 & 6.4 & 6.1 & 6.4 & 8.7 & 6.4 & 6.6 & 6.1 & 6.5 & 9.1 & 6.4 & 28.1 & 8.8 & 4.9 & 1.5 & 6.4 & 5.0 & 6.7 \\
\hline Elec Machinery & 21.6 & 18.7 & 9.6 & 12.9 & 9.3 & $11.0^{*}$ & 9.8 & 10.2 & 9.5 & 9.9 & 7.4 & 10.0 & 21.0 & 8.6 & 7.0 & 2.0 & 10.0 & 6.6 & 9.6 \\
\hline Transp Equip & 22.1 & 24.5 & 11.1 & 2.4 & 8.5 & $6.0^{*}$ & 10.3 & 9.9 & 12.0 & 10.7 & 6.0 & 10.9 & 27.6 & 3.5 & 8.2 & 6.7 & 9.3 & 3.3 & 7.7 \\
\hline Misc Manufact & 13.0 & 13.7 & 5.2 & 8.8 & 10.0 & 18.1 & 9.6 & 9.1 & 11.2 & 9.4 & 6.0 & 8.7 & 20.5 & 8.9 & 6.1 & 1.5 & 4.9 & 7.8 & 7.8 \\
\hline All Industries & 17.0 & 15.4 & 8.2 & 7.3 & 9.0 & 9.6 & 8.3 & 8.7 & 9.4 & 7.3 & 3.9 & 9.2 & 18.9 & 6.9 & 6.4 & 3.9 & 7.3 & 6.5 & 7.8 \\
\hline
\end{tabular}

- Estimated from incomplete data.

Estimated from incomplete data.
+ Prevailing rates, which include unilateral reductions in post-Kennedy round tariff rates.

Prevaling rates, which include unilateral reductions in post-Kennedy ro

Source: Deardorff and Stern (1983).

Table A2 - Weighted average applied tariff, First available year

\begin{tabular}{llll}
\hline Zone & Corresp. region & Tariff & Year \\
\hline Brazil & Brazil & 37.96 & 1989 \\
China & China & 36.41 & 1992 \\
ASEAN & East Asia (developing) & 13.53 & 1996 \\
RoEurope & Europe and Central Asia (developing) & 8.91 & 1996 \\
India & India & 76.28 & 1990 \\
Korea & Korea & 16.91 & 1988 \\
RoLAC & Latin America (developing) & 14.57 & 1996 \\
Mexico & Mexico & 13.03 & 1991 \\
MiddleEast & Middle-East and North Africa (developing) & 25.74 & 1996 \\
NorthAfr & Middle-East and North Africa (developing) & 25.74 & 1996 \\
RoW & Middle Income & 13.23 & 1996 \\
Russia & Russian Federation & 7.52 & 1993 \\
SouthAfr & South Africa & 13.42 & 1988 \\
RoAfr & Sub-Saharan Africa (developing) & 13.33 & 1996 \\
Turkey & Turkey & 5.37 & 1993 \\
\hline
\end{tabular}

Source: WDI. 


\section{APPENDIX B: COUNTRY CLASSIFICATION}

Table B1 - Country list, codes, income classes and region

\begin{tabular}{|c|c|c|c|c|c|c|c|c|c|}
\hline code & name & $\begin{array}{l}\text { Inc. } \\
\text { class }\end{array}$ & zone & Dvd. & code & name & $\begin{array}{l}\text { Inc. } \\
\text { class }\end{array}$ & zone & Dvd. \\
\hline AGO & Angola & $\mathrm{M}$ & SSA & 0 & EGY & Egypt, Arab Rep. & $\mathrm{M}$ & MENA & 0 \\
\hline ALB & Albania & $\mathrm{M}$ & ROW & 0 & ESP & Spain & $\mathrm{H}$ & EU27 & 1 \\
\hline ARE & United Arab & $\mathrm{H}$ & MENA & 0 & EST & Estonia & $\mathrm{H}$ & EU27 & 1 \\
\hline & Emirates & & & & ETH & Ethiopia & $\mathrm{L}$ & SSA & 0 \\
\hline ARG & Argentina & M & SAM & 0 & FIN & Finland & $\mathrm{H}$ & EU27 & 1 \\
\hline ARM & Armenia & M & ROW & 0 & FJI & Fiji & $\mathrm{M}$ & ROW & 0 \\
\hline AUS & Australia & $\mathrm{H}$ & ROW & 0 & FRA & France & $\mathrm{H}$ & EU27 & 1 \\
\hline AUT & Austria & $\mathrm{H}$ & EU27 & 1 & GAB & Gabon & M & SSA & 0 \\
\hline BDI & Burundi & $\mathrm{L}$ & SSA & 0 & GBR & United Kingdom & $\mathrm{H}$ & EU27 & 1 \\
\hline BEL & Belgium & $\mathrm{H}$ & EU27 & 1 & GEO & Georgia & $\mathrm{M}$ & ROW & 0 \\
\hline BEN & Benin & $\mathrm{L}$ & SSA & 0 & GHA & Ghana & $\mathrm{L}$ & SSA & 0 \\
\hline BFA & Burkina Faso & $\mathrm{L}$ & SSA & 0 & GIN & Guinea & $\mathrm{L}$ & SSA & 0 \\
\hline BGD & Bangladesh & $\mathrm{L}$ & ROAS & 0 & GMB & Gambia, The & $\mathrm{L}$ & SSA & 0 \\
\hline BGR & Bulgaria & M & EU27 & 1 & GNB & Guinea-Bissau & $\mathrm{L}$ & SSA & 0 \\
\hline BHR & Bahrain & $\mathrm{H}$ & MENA & 0 & GRC & Greece & $\mathrm{H}$ & EU27 & 1 \\
\hline BHS & Bahamas, The & $\mathrm{H}$ & SAM & 0 & GTM & Guatemala & M & SAM & 0 \\
\hline BLR & Belarus & M & ROW & 0 & GUY & Guyana & M & SAM & 0 \\
\hline BLZ & Belize & M & SAM & 0 & HKG & Hong Kong, China & $\mathrm{H}$ & ROAS & 0 \\
\hline BOL & Bolivia & M & SAM & 0 & HND & Honduras & M & SAM & 0 \\
\hline BRA & Brazil & M & BRA & 0 & HTI & Haiti & $\mathrm{L}$ & SAM & 0 \\
\hline BRB & Barbados & $\mathrm{H}$ & SAM & 0 & HUN & Hungary & $\mathrm{H}$ & EU27 & 1 \\
\hline BRN & Brunei Darussalam & $\mathrm{H}$ & ROAS & 0 & IDN & Indonesia & M & ROAS & 0 \\
\hline BTN & Bhutan & M & ROAS & 0 & IND & India & M & IND & 0 \\
\hline BWA & Botswana & M & SSA & 0 & & Ireland & $\mathrm{H}$ & EU27 & 1 \\
\hline CAF & $\begin{array}{l}\text { Central African } \\
\text { Republic }\end{array}$ & $\mathrm{L}$ & SSA & 0 & $\begin{array}{l}\text { IRL } \\
\text { IRN }\end{array}$ & Iran, Islamic Rep. & $\mathrm{M}$ & MENA & 0 \\
\hline CAN & Canada & $\mathrm{H}$ & ROW & 1 & ISL & Iceland & $\mathrm{H}$ & ROW & 1 \\
\hline CHE & Switzerland & $\mathrm{H}$ & ROW & 1 & ISR & Israel & $\mathrm{H}$ & MENA & 0 \\
\hline CHL & Chile & M & SAM & 0 & ITA & Italy & $\mathrm{H}$ & EU27 & 1 \\
\hline CHN & China & M & CHN & 0 & JOR & Jordan & M & MENA & 0 \\
\hline CIV & Cote d'Ivoire & M & SSA & 0 & JPN & Japan & $\mathrm{H}$ & JPN & 1 \\
\hline CMR & Cameroon & M & SSA & 0 & KAZ & Kazakhstan & $\mathrm{M}$ & ROW & 0 \\
\hline COG & Congo, Rep. & $\mathrm{L}$ & SSA & 0 & KEN & Kenya & $\mathrm{L}$ & SSA & 0 \\
\hline COL & Colombia & M & SAM & 0 & KGZ & Kyrgyz Republic & $\mathrm{L}$ & ROAS & 0 \\
\hline CPV & Cape Verde & M & SSA & $\begin{array}{l}0 \\
0\end{array}$ & KHM & Cambodia & $\mathrm{L}$ & ROAS & 0 \\
\hline $\begin{array}{l}\text { CRI } \\
\text { CZE }\end{array}$ & $\begin{array}{l}\text { Costa Rica } \\
\text { Czech Republic }\end{array}$ & $\begin{array}{l}\mathrm{M} \\
\mathrm{H}\end{array}$ & $\begin{array}{l}\text { SAM } \\
\text { EU27 }\end{array}$ & $\begin{array}{l}0 \\
1\end{array}$ & KOR & Korea, Rep. & $\mathrm{H}$ & ROAS & 0 \\
\hline DEU & Germany & $\mathrm{H}$ & EU27 & 1 & KWT & Kuwait & $\mathrm{H}$ & MENA & 0 \\
\hline DJI & Djibouti & M & SSA & 0 & LAO & Lao PDR & $\mathrm{L}$ & ROAS & 0 \\
\hline DNK & Denmark & $\mathrm{H}$ & EU27 & 1 & LBN & Lebanon & $\mathrm{M}$ & MENA & 0 \\
\hline DOM & Dominican Republic & M & SAM & 0 & LCA & St. Lucia & $\mathrm{M}$ & SAM & 0 \\
\hline DZA & Algeria & M & MENA & 0 & LKA & Sri Lanka & M & ROAS & 0 \\
\hline
\end{tabular}




\begin{tabular}{|c|c|c|c|c|c|c|c|c|c|}
\hline code & name & $\begin{array}{l}\text { Inc. } \\
\text { class }\end{array}$ & zone & Dvd. & code & name & $\begin{array}{l}\text { Inc. } \\
\text { class }\end{array}$ & zone & Dvd. \\
\hline LSO & Lesotho & $\mathrm{M}$ & SSA & 0 & SVK & Slovak Republic & $\mathrm{H}$ & EU27 & 1 \\
\hline LTU & Lithuania & $\mathrm{M}$ & EU27 & 1 & SWE & Sweden & $\mathrm{H}$ & EU27 & 1 \\
\hline LUX & Luxembourg & $\mathrm{H}$ & EU27 & 1 & SWZ & Swaziland & $\mathrm{M}$ & SSA & 0 \\
\hline LVA & Latvia & $\mathrm{M}$ & EU27 & 1 & SYR & Syrian Arab & $\mathrm{M}$ & MENA & 0 \\
\hline MAR & Morocco & M & MENA & 0 & & Republic & & & \\
\hline MDA & Moldova & $\mathrm{M}$ & ROW & 0 & TCD & Chad & $\mathrm{L}$ & SSA & 0 \\
\hline MDG & Madagascar & $\mathrm{L}$ & SSA & 0 & TGO & Togo & $\mathrm{L}$ & SSA & 0 \\
\hline MDV & Maldives & M & ROW & 0 & THA & Thailand & $\mathrm{M}$ & ROAS & 0 \\
\hline MEX & Mexico & $\mathrm{M}$ & SAM & 0 & TJK & Tajikistan & $\mathrm{L}$ & ROW & 0 \\
\hline MLI & Mali & $\mathrm{L}$ & SSA & 0 & TTO & Trinidad and Tobago & $\mathrm{H}$ & SAM & 0 \\
\hline MLT & Malta & $\mathrm{H}$ & EU27 & 1 & TUN & Tunisia & $\mathrm{M}$ & MENA & 0 \\
\hline MNG & Mongolia & M & ROAS & 0 & TUR & Turkey & M & MENA & 0 \\
\hline MOZ & Mozambique & $\mathrm{L}$ & SSA & 0 & TZA & Tanzania & $\mathrm{L}$ & SSA & 0 \\
\hline MRT & Mauritania & $\mathrm{L}$ & SSA & 0 & UGA & Uganda & $\mathrm{L}$ & SSA & 0 \\
\hline MUS & Mauritius & $\mathrm{M}$ & SSA & 0 & UKR & Ukraine & $\mathrm{M}$ & ROW & 0 \\
\hline MWI & Malawi & $\mathrm{L}$ & SSA & 0 & URY & Uruguay & $\mathrm{M}$ & SAM & 0 \\
\hline MYS & Malaysia & M & ROAS & 0 & USA & United States & $\mathrm{H}$ & USA & 1 \\
\hline NER & Niger & $\mathrm{L}$ & SSA & 0 & VCT & St. Vincent and the & $\mathrm{M}$ & SAM & 0 \\
\hline NGA & Nigeria & $\mathrm{M}$ & SSA & 0 & VEN & Venezuela, RB & $\mathrm{M}$ & SAM & 0 \\
\hline NIC & Nicaragua & M & SAM & 0 & VNM & Vietnam & $\mathrm{L}$ & ROAS & 0 \\
\hline NLD & Netherlands & $\mathrm{H}$ & EU27 & 1 & VUT & Vanuatu & $\mathrm{M}$ & ROW & 0 \\
\hline NOR & Norway & $\mathrm{H}$ & ROW & 1 & YEM & Yemen, Rep. & $\mathrm{L}$ & MENA & 0 \\
\hline NPL & Nepal & $\mathrm{L}$ & ROAS & 0 & $\mathrm{ZAF}$ & South Africa & M & SSA & 0 \\
\hline NZL & New Zealand & $\mathrm{H}$ & ROW & 1 & ZMB & Zambia & $\mathrm{L}$ & SSA & 0 \\
\hline OMN & Oman & $\mathrm{H}$ & MENA & 0 & & & & & \\
\hline PAK & Pakistan & $\mathrm{M}$ & ROAS & 0 & & & & & \\
\hline PAN & Panama & $\mathrm{M}$ & SAM & 0 & & & & & \\
\hline PER & Peru & $\mathrm{M}$ & SAM & 0 & & & & & \\
\hline PHL & Philippines & M & ROAS & 0 & & & & & \\
\hline PNG & Papua New Guinea & M & ROW & 0 & & & & & \\
\hline POL & Poland & $\mathrm{M}$ & EU27 & 1 & & & & & \\
\hline PRT & Portugal & $\mathrm{H}$ & EU27 & 1 & & & & & \\
\hline PRY & Paraguay & $\mathrm{M}$ & SAM & 0 & & & & & \\
\hline QAT & Qatar & $\mathrm{H}$ & MENA & 0 & & & & & \\
\hline ROM & Romania & $\mathrm{M}$ & EU27 & 1 & & & & & \\
\hline RUS & Russian Federation & M & RUS & 0 & & & & & \\
\hline RWA & Rwanda & $\mathrm{L}$ & SSA & 0 & & & & & \\
\hline SAU & Saudi Arabia & $\mathrm{H}$ & MENA & 0 & & & & & \\
\hline SDN & Sudan & $\mathrm{M}$ & MENA & 0 & & & & & \\
\hline SEN & Senegal & $\mathrm{L}$ & SSA & 0 & & & & & \\
\hline SGP & Singapore & $\mathrm{H}$ & ROAS & 0 & & & & & \\
\hline SLB & Solomon Islands & $\mathrm{M}$ & ROW & 0 & & & & & \\
\hline SLE & Sierra Leone & $\mathrm{L}$ & SSA & 0 & & & & & \\
\hline SUR & Suriname & $\mathrm{M}$ & SAM & 0 & & & & & \\
\hline
\end{tabular}


Table B2 - Labels for zones and income groups:

\begin{tabular}{lll}
\hline Label & Zone & Developed / Developing \\
\hline EU27 & European Union & All developed \\
MENA & Middle-East and North Africa & All developing \\
SSA & Sub-Saharan Africa & All developing \\
USA & United States of America & Developed \\
JPN & Japan & Developed \\
CHN & China & Developing \\
IND & India & Developing \\
BRA & Brazil & Developing \\
RUS & Russian Federation & Developing \\
ROAS & Rest of Asia & All developing \\
SAM & Latin America & All developing \\
ROW & Rest of the World & All developing excepted Switzerland, New \\
H & High income (WB) & Zealand, Iceland, Norway, Australia and Canada \\
M & Medium income (WB) & \\
L & Low income (WB) & \\
\hline
\end{tabular}

